[This document contains the author's accepted manuscript. For the publisher's version, see the link in the header of this document.]

\title{
To What Extent Are Investment Bank-Differentiating Factors Relevant For Firms Floating Moderate-Sized IPOs?
}

\author{
Kedar S. Kulkarni \\ Duquesne Capital Management LLC \\ 40 W. 57th Street; 25th Floor \\ New York NY 10019 \\ kedar@duquesne.com \\ Tarun Sabarwal** \\ Department of Economics, Box 1208 \\ Washington University in St. Louis \\ One Brookings Drive \\ St. Louis MO 63130-4899 \\ sabarwal@wustl.edu
}

\begin{abstract}
Paper citation:
Kulkarni, Kedar and Tarun Sabarwal (2007): "To What Extent Are Investment

Bank-Differentiating Factors Relevant For Firms Floating Moderate-Sized IPOs?"

Annals of Finance, 3(3), July, 297-327.
\end{abstract}

\section{Keywords:}

Investment Banking; Initial Public Offering; Differentiating Factors; Concentration; 7 percent puzzle

\begin{abstract}
:
One explanation provided for the relatively high and increasingly stable spreads for moderate-sized IPOs (\$20-\$80 million) documented in Chen and Ritter (2000) is that issuing firms focus less on price and more on a combination of investment bank-differentiating factors (such as underwriter prestige, analyst coverage, industry expertise, under-pricing, price stabilization activities, liquidity provision, and so on,) and banks use industry-based differentiation as a source of market power. Using a new approach developed in a model of firm location choice due to Ellison and Glaeser (1997), this paper presents some evidence on the combined relevance of such bank-differentiating factors, over and above bank size, for firms choosing investment banks for floating IPOs. For moderate-sized IPOs, there is a little, but not much evidence that such factors are a good explanation for high and increasingly stable spreads. Other than in a few of the largest industries, bank-differentiating factors are not significantly relevant for a large proportion of industries. Moreover, one aggregate measure of differentiation is declining over time.
\end{abstract}




\title{
To What Extent Are Investment Bank-Differentiating Factors Relevant For Firms Floating Moderate-Sized IPOs?*
}

\author{
Kedar S. Kulkarni \\ Duquesne Capital Management LLC \\ 40 W. $57^{\text {th }}$ Street; $25^{\text {th }}$ Floor \\ New York NY 10019 \\ kedar@duquesne.com \\ Tarun Sabarwal ${ }^{* *}$ \\ Department of Economics, Box 1208 \\ Washington University in St. Louis \\ One Brookings Drive \\ St. Louis MO 63130-4899 \\ sabarwal@wustl.edu
}

First Draft: May 2004

This version: June 7, 2006

JEL Numbers: G24, G31, L11

Keywords: Investment Banking, Initial Public Offering, Differentiating Factors, Seven Percent Puzzle

\footnotetext{
* We are grateful to Preston McAfee for suggesting this approach to the problem, to Jay Ritter for providing an updated list of IPOs, and to Robert Anderson and anonymous referees for helpful comments. We are grateful to seminar audiences at the University of Texas at Austin and Macalester College for helpful comments.

** Corresponding author
} 


\title{
To What Extent Are Investment Bank-Differentiating Factors Relevant For Firms Floating Moderate-Sized IPOs?
}

\begin{abstract}
One explanation provided for the relatively high and increasingly stable spreads for moderate sized IPOs (\$20-\$80 million) documented in Chen and Ritter (2000) is that issuing firms focus less on price and more on a combination of investment bank-differentiating factors (such as underwriter prestige, analyst coverage, industry expertise, under-pricing, price stabilization activities, liquidity provision, and so on,) and banks use industry-based differentiation as a source of market power. Using a new approach developed in a model of firm location choice due to Ellison and Glaeser (1997), this paper presents some evidence on the combined relevance of such bank-differentiating factors, over and above bank size, for firms choosing investment banks for floating IPOs. For moderate-sized IPOs, there is a little, but not much evidence that such factors are a good explanation for high and increasingly stable spreads. Other than in a few of the largest industries, bank-differentiating factors are not significantly relevant for a large proportion of industries. Moreover, one aggregate measure of differentiation is declining over time.
\end{abstract}




\section{Introduction}

As shown in the well-known paper by Chen and Ritter (2000), in the market for initial public offerings (IPOs), the moderate-sized IPO market (IPOs in the range \$20-\$80 million) has high and increasingly stable prices - with gross spreads of about 7 percent of IPO proceeds. ${ }^{1}$ This is in contrast to differential and significantly lower pricing observed both in IPO markets in other countries and in markets for seasoned equity offerings (SEOs), whether in the U.S. or abroad.

One of the several explanations postulated for this "seven percent puzzle" is that issuing firms may focus less on price and more on some combination of investment bankdifferentiating factors, (such as underwriter prestige, analyst coverage, industry expertise, under-pricing, price stabilization activities, liquidity provision, and so on,) and investment banks use industry-based differentiation as a source of market power.

Earlier work has presented some evidence regarding this explanation. For example, Krigman, Shaw, and Womack $(2001)^{2}$ find that in the decision of firms to switch from their IPO-underwriter to a different SEO-underwriter, IPO-underwriting fees charged are

\footnotetext{
${ }^{1}$ As they show, during the period 1995-1998, about 91 percent of firms floating IPOs between 20 and 80 million dollars paid a gross spread of exactly 7 percent to raise this capital. Moreover, the use of this 7 percent spread has increased over time; from 26 percent of all moderate-sized IPOs in 1985-87, to 75 percent in 1988-94, to 91 percent in 1995-98, and more recently, to 96 percent in 1999-03.

2 They look at 572 firms with initial public offerings during 1993-95 that returned for a seasoned equity offering in the next three years, and 180 of which switched underwriters, and on surveys of decisionmakers (CFOs and CEOs) of 62 of these switching firms. Their focus is slightly different, in that they consider reasons for firms to switch underwriters for a SEO. Of course, an important distinction between the IPO and SEO decision is that the SEO firm has a history of securities market evaluation of its prospects, and therefore, the uncertainty regarding its prospects is different from that of an IPO firm. Consequently, firm decisions in each case are potentially different. Moreover, the data here cover a different time period, 1985-2003, the analysis focuses on moderate-sized IPOs, and the analysis does not use surveys.
} 
accorded low relevance, whereas graduating to an underwriter with higher prestige and with better analyst coverage are accorded high relevance. Moreover, Benveniste, Ljungqvist, Wilhelm, and Yu (2003) show that IPO terms and the decision of IPO-issuing firms to carry through with an offering are conditioned on the experience of their primary market contemporaries. Furthermore, Logue, Rogalski, Seward, and Foster-Johnson (2002) find that underwriter reputation is a significant determinant of pre-market underwriter activities, is weakly related to after-market price stabilization activities, and is unrelated to issuer returns. Additional evidence for the role of underwriter reputation and industry-specific spillovers is provided in, among others, Beatty and Ritter (1986), Carter and Manaster (1990), Chemmanur and Fulghieri (1994), Carter, Dark and Singh (1998), Dunbar (2000), Benveniste, Busaba, and Wilhelm (2002), and Lowry and Schwert (2002).

Using a new approach developed in a relatively recent model of firm location choice due to Ellison and Glaeser (1997), ${ }^{3}$ this paper conducts a new test of the extent to which this explanation holds in the data. ${ }^{4}$

Intuitively, the test proposed by Ellison and Glaeser (henceforth, EG) can be motivated by a simple example, as follows. Suppose there are two investment banks (indexed 1 and

\footnotetext{
${ }^{3}$ Their model is applied here as a discrete-choice model of a firm's optimal choice of an investment bank. Notably, the model focuses on firm decision-making, and does not model investment bank decision-making explicitly. Details are provided below.

${ }^{4}$ In particular, this paper does not investigate the question of implicit or explicit collusion. For references to that strain of the literature, confer Chen and Ritter (2000), which uses arguments from Chen (1998), Dutta and Madhavan (1997), Rotember and Saloner (1986), and from Bhagat and Frost (1986), Booth and Smith (1986), and other papers, including Ljunqvist and Wilhelm, Jr. (1999), Hansen (2001), Christie and Schulz (1994), Christie, Harris, and Schulz (1994). A recent survey of under-pricing, share allocation, and overall IPO activity is presented in Ritter and Welch (2002).
} 
2), each with one-half the market share of all IPOs, and suppose IPOs are floated by firms in two industries (indexed A and B), each contributing one-half of value of all IPOs. If bank 1 possesses or provides a combination of differentiating factors that are relatively more valuable for firms in industry A, then a greater proportion of industry A firms optimally choose (or cluster with) bank 1. Similarly, if bank 2 possesses or provides a combination of factors that are relatively more valuable for firms in industry $\mathrm{B}$, then a greater proportion of industry B firms optimally choose (or cluster with) bank 2. Suppose firm choices imply the following outcome: four-fifths of IPO value of industry A goes to bank 1 , and one-fifth to bank 2, and symmetrically for industry B. In this example, the observed difference between a bank's share of an industry (four-fifths or one-fifth) and a bank's share of all IPOs (one-half) arises from relevance of bank-differentiating factors. In other words, if banks provide a combination of differentiating factors, then observed firm clustering with banks would be related to the extent such combinations of factors are valuable for firm choices.

Using EG's discrete-choice model, differential clustering of firms with banks is generated by two parameters that are viewed in terms of two broad categories of bankdifferentiating factors - industry-specific information spillovers and bank-specific reputation factors, such as underwriter prestige. ${ }^{5}$ For each industry, the stronger is the

\footnotetext{
${ }^{5}$ Intuitively, the parameter for industry-specific factors is a reduced form index of relevance of factors related to industry-specific information spillovers, such as better investment bank placements of IPO shares (whether through book-building, under-pricing, or share allocation) depending on number of industry deals done, more expert analyst coverage depending on number of industry deals done, economies of scope in information production costs (including lower marketing costs and better post-IPO stock liquidity) depending on number of industry deals done, and so on. Similarly, the parameter for bank-specific factors is a reduced form index of relevance of factors related to underwriter prestige. That is, firms in a particular industry might choose an investment bank partly because of its reputation, indicating better bank placement
} 
relevance of these parameters, the greater is clustering of this industry's firms with particular banks.

Notice that some clustering of firms with banks can occur randomly as well, and therefore, EG's test of differential clustering takes as a benchmark the outcome that would occur if firms choose banks randomly. This benchmark assumes that in the absence of relevance of bank-differentiating factors, the expected probability that a firm chooses a particular bank is the bank's market share. (Intuitively, in the absence of relevance of bank-differentiating factors, firms choose banks as if by throwing darts randomly at a map of all banks, with size of a bank given by its market share. ${ }^{6}$ ) EG's results provide industry-level tests for when observed clustering is different from benchmark, and this test is used here to determine existence of relevance of bankdifferentiating factors for each industry.

Based on observed clustering, EG's results derive a measure of the strength of a combination of these two parameters. This measure is termed a differentiation index. It takes a value between 0 and 1, (with higher parameter values implying greater index value,) it is comparable across industries, across segments of the IPO market, and across time.

of IPO shares depending on underwriter reputation, an overall reputation for better analysts or greater analyst coverage, a reputation for price stabilization activities or for liquidity, and so on.

${ }^{6}$ A caveat to this benchmark is that bank size might be positively related to underwriter prestige. (This is not always the case. For example, Chen and Ritter (2000) document existence of small niche investment banks in other parts of this market.) To the extent that this is the case, the test here provides for relevance of investment bank-differentiating factors over and above bank size. In this sense, the test here is a stricter test for relevance of bank-differentiating factors. 
An important limitation of this model is that it cannot provide measures of direct effects of specific bank-differentiating factors. Indeed, (as can be seen in the section describing the model,) the differentiation index is invariant to particular compositional changes; that is, it is observationally equivalent to particular changes in the two parametric components of differentiation. Therefore, this work cannot address the role of specific bankdifferentiating factors.

The analysis here can (and does) inquire into the broader question of relevance of the hypothesized bank-provided industry-based differentiation, regardless of the form it may take, for firms choosing investment banks to float IPOs. Therefore, while this work cannot address the relevance of specific bank-differentiating factors such as the specific role of greater analyst coverage, or of star analysts, or of bank prestige, or of industry expertise, it can (and does) address the broader question of whether observed firm choices are consistent with the view that firms in an industry find value in some combination of a bundle of bank-differentiating factors. This broader test can serve a useful purpose, because different bank-differentiating factors can potentially interact with each other. For example, suppose firms in an industry treat a bank's industry expertise and a bank's prestige as close substitutes, (perhaps because each factor independently allows a firm's IPO to be placed on attractive terms,) and value these equally. In this case, if one bank provides industry expertise but not prestige, and another bank provides prestige but not industry expertise, then even though each bank is providing "differentiated" services, neither has significant market power, because products of both banks are close substitutes, and we would not expect to observe "high" prices based on 
market power. More generally, the test here allows for a combination of differentiating factors to influence firm profits and firm choice.

An appealing feature of EG's work is that the differentiation index is a "model-based" index, and it yields a testable prediction directly from the model. A secondary advantage of this model is that it side-steps some limitations of empirical measurement. For example, it may be hard to measure (and consequently, to separately identify the role of) the different bank-differentiating factors mentioned above. ${ }^{7}$ Moreover, several factors mentioned above can influence the role of both underwriter prestige and industry expertise, and therefore, empirically, it may be hard to separate the specific contribution of a given factor on either parameter. These potential limitations are side-stepped here, because the analysis here represents only a combined effect of these two parameters.

The dataset used here is derived from SDC data for 1985-2003, and it is bench-marked to updates to data in Chen and Ritter (2000). Experiments are conduc ted at the level of fourdigit SIC codes (SIC4), three-digit SIC codes (SIC3), two-digit SIC Codes (SIC2), and some alternative sub-samples. Within these classifications, experiments are conducted for the overall period (1985-03), for three sub-periods used in Chen and Ritter (2000) 1985-87, 1988-94, 1995-98 - and for the fourth more recent period 1999-03.

To investigate the explanation that Chen and Ritter's results for moderate-sized IPOs are consistent with explanations based on investment bank-differentiating factors, the

\footnotetext{
${ }^{7}$ For example, confer Krigman, Shaw, and Womack (2001) for some issues that arise in inferring highquality underwriting firms.
} 
primary hypothesis here is that for moderate-sized IPOs, bank-differentiating factors are relevant for firms choosing banks to underwrite IPOs. This is an existence hypothesis, and it can be viewed as follows. Suppose firms issuing moderate-sized IPOs focus less on price and more on investment bank-differentiating factors, and investment banks use industry-based differentiation as a source of market power. If firms in an industry perceive investment banks as differentiated, and if firms value such bank-differentiating factors more than raw bank size, then firms in this industry would cluster with (or choose) banks differently from benchmark. There is a little, but not much evidence for this existence of differentiation hypothesis.

For moderate-sized IPOs issued during 1985-2003, in the base case (SIC4 industries), about 12 percent (36 of 300) of the industries exhibit existence of differentiation. Moreover, there is no clear pattern that if differentiation exists for an industry then it necessarily exists for industries with similar SIC codes, or if differentiation exists for an industry in one period then it necessarily exists in other periods as well. Experiments to control for the effect of distribution of industries on test results yield a number of about 25 percent ( 24 percent at the median, and 26 percent at the mean). These experiments show that except for a handful of the very largest industries, the probability of existence of differentiation remains small. When considering a non-outlier sub-sample, differentiation exists in about 16 percent of the industries. When considering SIC 3 industries, differentiation exists in about 13 percent of industries, and when considering SIC2 industries, differentiation exists in about 24 percent of industries. Results for the 
sub-periods are similar, and are more likely to yield lower numbers. The high frequency of technology IPOs during 1998-2000 does not appear to affect these results.

Industries that exhibit differentiation appear to be diffused across the space of SIC codes, and include established industries, newer industries, and a mixture of the two. An aggregate measure of differentiation is declining over time, independent of SIC4, SIC3, or SIC2 classification. Therefore, one may conjecture that over time, on average, the moderate-sized IPO segment is moving toward less differentiation.

The paper proceeds as follows. Section 2 describes an application of the Ellison-Glaeser model to this paper. Section 3 describes the data and presents the results. Section 4 concludes.

\section{Model}

The discrete-choice model of firm choice of investment bank used here is due to EG. ${ }^{8}$ Their model was formulated to understand clustering of manufacturing industries in different geographic areas, over and above clustering of overall manufacturing. In their model, profit-maximizing firms in an industry choose among different geographic areas (states) in which to locate. Differential clustering is generated by state-specific factors, thought of as natural advantages from locating in a particular state (for example, good weather in California provides a natural advantage for wine production in California, coastal location of Virginia provides a natural advantage for ship-building in Virginia),

\footnotetext{
${ }^{8}$ This section draws heavily on Ellison and Glaeser (1997). Interested readers can yield additional insights about their model, and consequently, its application here, by referring to their lucid and wonderfully intuitive exposition.
} 
and spillover factors, thought of as spillovers from location of other firms (for example, technological spillovers and labor market gains from computer firms in Silicon Valley, or car manufacturers in Detroit).

Their model and results are recast for the situation analyzed here. To facilitate reference to their model, same notation is used here, with minor exceptions. Moreover, direct comparisons of the application here and the application in EG are provided as well.

Suppose, similar to EG, there are a finite number of potential investment banks, indexed by $i$. Consider an industry $n$ with $N$ firms, each firm choosing sequentially which investment bank $i$ to use for an initial public offering. Each firm is small relative to a bank and cannot affect a bank's size. Denote by $v_{k}$ the choice of a bank by firm $k$, and suppose profits to firm $k$ from choosing bank $i$ are

$$
\log \pi_{k i n}=\log \overline{\pi_{i n}}+g_{i n}\left(v_{1}, \cdots, v_{k-1}\right)+\varepsilon_{k i n},
$$

where $\pi_{i n}^{-}$are random variables measuring the impact on firm profits from bank $i$ 's characteristics, (such as underwriter prestige,) $g_{\text {in }}$ measures the impact on firm profits from bank $i$ 's industry expertise (depending on choices of other firms), ${ }^{9}$ and $\varepsilon_{\text {kin }}$ is a firm idiosyncratic shock. $^{10}$

\footnotetext{
${ }^{9}$ Additional structure regarding the form of $g_{i}$ is provided below.

${ }^{10}$ For reference, in EG, each of $\mathrm{N}$ firms in an industry choose sequentially a geographic area (state) $i$ in which to locate. Firm profits from choosing area $i$ depend on profitability from characteristics of area $i$, and industry spillovers in area $i$, depending on choices of other firms, as above.
} 
As usual, for fixed $n$, when $\varepsilon_{k i n}$ are independent Weibull, are independent of $\pi_{\text {in }}^{-}$, and when firm profits do not depend on industry expertise, (that is, for each $i, g_{\text {in }}$ is identically 0,) this model coincides with a standard logit model. In this case, firm $k$ 's conditional probability of choosing bank $i$ is $\operatorname{prob}\left\{v_{k}=i \overline{\pi_{1 n}}, \cdots, \overline{\pi_{M n}}\right\}=\frac{\overline{\pi_{i n}}}{\sum_{j} \overline{\pi_{j n}}}$. It is assumed, as in EG, that

$$
E_{\overline{\pi_{1 n}}, \cdots \overline{\pi_{M n}}} \frac{\overline{\pi_{i n}}}{\sum_{j} \overline{\pi_{j n}}}=x_{i}
$$

where $x_{i}$ is bank $i$ 's share of all IPOs. ${ }^{11}$ This serves two purposes.

First, notice that this model focuses on firm decision-making, and each firm is assumed to be small relative to a bank, and therefore, the modeling assumption is that a firm takes $x_{i}$ as exogenous ly given. This model does not explain a bank's decision- making process, and of course, a bank's decision- making affects a bank's market share. The condition above can be viewed in terms of closing the model, because it implies (using EG's description; confer the next footnote) that on average, the model reproduces the overall distribution of IPO activity. Thus, although bank decision- making is not explained in the model, the above condition can be viewed as an expected market clearing condition; it requires that expected firm choices are consistent with realized bank shares (that may depend on bank decisions not modeled). ${ }^{12}$

\footnotetext{
${ }^{11}$ Notice that the left-hand side of the equality is specific to an industry, but the right-hand side is the share of all IPOs under consideration, not just for a particular industry.

${ }^{12}$ In EG, the variable $x_{i}$ is state $i$ 's share of all manufacturing employment, and it is assumed to be exogenous. Of course, in principle, a state can affect its share of manufacturing employment by providing incentives to attract certain industries; for example, attracting technology corridors in Virginia, or attracting car manufacturing in Alabama or Georgia. One may address this effect indirectly by postulating
} 
Second, if variance of probability of firm's choice of bank is zero, then firms choose banks independently, with probability $x_{i}$, as if by throwing darts at a map of all banks with size of bank given by its market share. This formulates a benchmark.

For firms in this industry, the importance of underwriter prestige is incorporated in the model by assuming (as in EG) that there is a parameter $\delta_{n}{ }^{\text {pres }} \in[0,1]$ specific to the industry such that the joint distribution of $\overline{\pi_{i n}^{-}}$satisfies $\operatorname{var}\left(\frac{\overline{\pi_{i n}}}{\sum_{j} \overline{\pi_{j n}}}\right)=\delta_{n}{ }^{p r e s} x_{i}\left(1-x_{i}\right)$. This parameter is termed underwriter prestige, ${ }^{13}$ and it is interpreted as a combined (and reduced form) measure of relevance to this industry of factors related to underwriter prestige. ${ }^{14}$ When $\delta_{n}{ }^{\text {pres }}=0$, underwriter prestige has no impact on a firm's choice, (and choices are as in the standard logit model,) and underwriter prestige is relatively more important as $\delta_{n}{ }^{\text {pres }}$ increases. ${ }^{15}$

\footnotetext{
that although state decision-making is not explained in the model, the model is closed in the sense that on average, the model reproduces the overall distribution of manufacturing activity (words in italics from EG, page 893, explaining the above condition on expectation of relative profitability). However, it is a reasonable conjecture that a state can affect its own manufacturing activity less than a bank can affect its own market share, and in this sense, the exogeneity assumption is closer to reality in EG.

${ }^{13}$ In EG, the analogous parameter is termed natural advantage, and it indexes importance of state characteristics for firms in an industry.

${ }^{14}$ As mentioned above, firms in a particular industry might choose an investment bank partly because of its reputation, indicating the relevance of investment bank-specific factors, such as better bank placement of IPO shares depending on underwriter reputation, an overall reputation for better analysts or greater analyst coverage, a reputation for price stabilization activities or for liquidity, and so on.

${ }^{15}$ As shown in EG, an example of this specification is if the $\bar{\pi}_{i}$ are independent random variables scaled to have a chi-squared distribution with $x_{i} 2\left(1-\delta_{n}{ }^{\text {pres }}\right) / \delta_{n}{ }^{\text {pres }}$ degrees of freedom. Moreover, in this case, $\operatorname{var}\left(\pi_{i n}^{-}\right)=x_{i} \delta_{n}{ }^{p r e s} /\left(1-\delta_{n}{ }^{p r e s}\right)$, so that as $\delta_{n}{ }^{\text {pres }}$ approaches 1 , underwriter prestige tends to dominate firmspecific idiosyncratic factors.
} 
For firms in this industry, the importance of investment bank industry expertise (or industry experience, or industry knowledge) is captured by $g_{i n}$, and it depends on choices of other firms. To make the model tractable, these benefits are assumed (as in EG) to be of the following form. For every pair of firms, either there is a benefit to these firms from choosing the same bank, or not. For tractability, it is assumed that these benefits are either extremely important or not important at all. That is, for every pair of firms, if there are benefits from same choice, then firms optimally choose the same bank, (otherwise they have negative infinite profits,) and if there are no benefits from same choice, then choice of either firm has no effect on choice of the other firm. The probability that a pair of firms has such extreme benefits from same choice is denoted $\delta_{n}{ }^{\text {expe }} \in[0,1]$. This parameter is termed industry expertise, ${ }^{16}$ and it is interpreted as a combined (and reduced form) measure of relevance to this industry of factors related to an underwriter's industry expertise. ${ }^{17}$ More formally, it is assumed that

$$
\log \pi_{k i n}=\log \overline{\pi_{i n}}+\sum_{l \neq k} e_{k l n}\left(1-u_{l i}\right)(-\infty)+\varepsilon_{k i n}
$$

where $e_{k l n}$ is an indicator for existence of benefits from same choice, with probability of existence of such benefits given by $\delta_{n}{ }^{\text {expe }}, u_{l i}$ is an indicator for whether firm $l$ chooses bank $i$, and the other variables are as before, with $\varepsilon_{k i n}$ independent of $e_{k l n}$. It is assumed further (as in EG) that among pairs of firms, the relationship of existence of benefits from

\footnotetext{
${ }^{16}$ In EG, the analogous parameter is termed spillovers, and it indexes benefits to firms from location choices of other firms. As they mention, such spillovers include technological spillovers, gains from labor markets, gains from interfirm trade, and so on.

${ }^{17}$ As mentioned above, some firms in an industry might choose an investment bank partly because this bank has successfully underwritten IPOs for other firms in the same industry, indicating the relevance of industry-specific information spillovers, such as better investment bank placements of IPO shares (whether through book-building, under-pricing, or share allocation) depending on number of industry deals done, more expert analyst coverage depending on number of industry deals done, economies of scope in information production costs (including lower marketing costs and better post-IPO stock liquidity) depending on number of industry deals done, and so on.
} 
same choice is symmetric and transitive. (That is, for each $n, e_{k l n}=1 \mathrm{implies} e_{l k n}=1$, and $e_{k l n}=1$ and $e_{l m n}=1$ implies $e_{k m n}=1$.) This implies that the resulting distribution of firm choices is independent of the order in which firms make choices. ${ }^{18}$

This model specification implies a particular relationship between observed firm choices in an industry and the strength of a combination of $\delta_{n}{ }^{\text {pres }}$ and $\delta_{n}{ }^{\text {expe }}$ for this industry, as follows. As in EG, let $z_{k n}$ be the relative size of firm $k$ 's IPO to industry IPOs, ${ }^{19}$ and let $u_{k i n}$ indicate if firm $k$ chooses bank $i$. Then bank $i$ 's share of this industry's IPOs is $s_{\text {in }}=\sum_{k} z_{k n} u_{\text {kin }}$. Therefore, a measure of the extent to which firms are more or less clustered with investment banks, relative to a bank's share of all IPOs, is $D_{n}=\sum_{i}\left(s_{i n}-x_{i}\right)^{2}$. This can be viewed as a gross measure of relevance of bankdifferentiating factors for firm choice. Suppressing the industry index in what follows, as shown in proposition 1 in $\mathrm{EG}$,

$$
E(D)=\left(1-\sum_{i} x_{i}^{2}\right)[\delta+(1-\delta) H]
$$

where $\delta=\delta^{\text {pres }}+\delta^{\text {expe }}-\delta^{\text {pres }} \delta^{\text {expe }}$, and $H=\sum_{k} z_{k}^{2}$ can be interpreted as an Herfindahl index of firm sizes. It is easy to see that $0 \leq \delta \leq 1$, that $\delta=0 \Leftrightarrow \delta^{\text {pres }}=\delta^{\text {expe }}=0$, that $\delta=1 \Leftrightarrow \delta^{\text {pres }}=1$ or $\delta^{\text {expe }}=1$, and that $\delta$ is observationally equivalent to particular compositional changes in $\delta^{\text {pres }}$ and $\delta^{\text {expe }}$.

\footnotetext{
${ }^{18}$ As noted in EG (page 895, footnote 4), for each $n$, the joint distribution of $e_{k l n}$ is not fully specified here. As EG note, the computation of $\mathrm{E}\left(\mathrm{D}_{n}\right)$ below is valid for all distributions satisfying the conditions here. As EG note, one such joint distribution is where the $e_{k n l}$ are perfectly correlated; that is, with some probability $\gamma_{0}$, all firms are completely interdependent, and with probability $1-\gamma_{0}$, all firm profits are independent.

${ }^{19}$ This calculation measures firm size.
} 
Under the null hypothesis $\delta^{\text {pres }}=\delta^{\text {expe }}=0, E(D)=\left(1-\sum_{i} x_{i}^{2}\right) H$, and as shown in EG,

$$
\operatorname{var}(D)=2\left\{H^{2}\left[\sum x_{i}^{2}-2 \sum x_{i}^{3}+\left(\sum x_{i}^{2}\right)^{2}\right]-\sum_{j} z_{j}^{4}\left[\sum x_{i}^{2}-4 \sum x_{i}^{3}+3\left(\sum x_{i}^{2}\right)^{2}\right]\right\}
$$

Consequently, computing $D$ and comparing it with $\left(1-\sum_{i} x_{i}^{2}\right) H$ provides a test for existence of bank-differentiating factors.

Moreover, an index of the strength of bank-differentiating factors is

$$
\delta=\frac{\sum_{i}\left(s_{i}-x_{i}\right)^{2}-\left(1-\sum_{i} x_{i}^{2}\right) H}{\left(1-\sum_{i} x_{i}^{2}\right)(1-H)}
$$

As shown in detail in EG, this index is an unbiased estimate of $\delta^{\text {pres }}+\delta^{\text {expe }}-\delta^{\text {pres }} \delta^{\text {expe }}$, it is comparable across industries in which firms float IPOs of different sizes, it is comparable across different segments of the IPO market, and it is comparable across time.

\section{Data and Analysis}

To keep this analysis consistent with Chen and Ritter (2000), the dataset used here is similar to the one they used, and is updated for more recent years. ${ }^{20}$ The data consist of 4,181 firm commitment IPOs, each for $\$ 20$ million or more, ${ }^{21}$ in 544 four-digit SIC code industries from January 1985 through December 2003, derived from the New Issues

\footnotetext{
${ }^{20}$ There have been some updates to their data, since their paper was published. We are very grateful to Professor Ritter for providing us with an updated list of IPOs over \$20 million for 1985-98. This list was used to refine SDC data. For reference, the number of above \$20 million IPOs over 1985-98 in Chen and Ritter is 3,203 , in the updated list, it is 3,229 , and in our data, it is 3,196. Moreover, the number of moderate-sized IPOs over 1985-98 in Chen and Ritter is 2,488, and in our data, it is 2,506. Furthermore, for each of the different sub-periods considered here, sub-period results for frequency of 7 percent IPOs in Chen and Ritter are replicated here to within 0.3 percentage points.

${ }^{21}$ All dollars are in constant 1997 CPI dollars.
} 
database of Securities Data Corporation (SDC). As in Chen and Ritter, ADRs, REITS, and unit offerings are excluded from the sample, as are 11 observations with unknown underwriters. Seven observations with SIC codes that cannot be matched to a master list of SIC codes are assigned codes based on observables such as industry type reported in the data. Industries are identified using four-digit SIC codes reported in the data.

The analysis here focuses on IPOs between $\$ 20$ million and \$80 million (moderate-sized IPOs). The dataset used for moderate-sized IPOs consists of 3,101 moderate-sized IPOs in 474 SIC4 industries from January 1985 through December 2003. Figure 1 extends Chen and Ritter's chart (Figure 1 in their paper) to include recent years, and it shows that spreads for moderate-sized IPOs have cont inued to converge to 7 percent. For the most recent period (1999-03), 96 percent of moderate-sized IPOs were priced at 7 percent. Additional data are provided in Table 1.

In the moderate-sized IPO market, the mean bank market share is small, at about 0.006 (6/10 of a percent), median is 0.001 , and standard deviation is 0.013 . However, consistent with existing information, the combined market share of the top 10 banks is about 50 percent, that of the top 25 banks is about 75 percent, and that of the top 50 banks is about 91 percent, and the remaining banks account for the remainder of the market share. ${ }^{22}$ For moderate-sized IPOs, the correlation between bank market share and the average spread charged by the bank is low, at about -0.06 .

\footnotetext{
${ }^{22}$ Additional information about different aspects of the structure of banks is provided in Hansen (2001).
} 
As described above, to investigate the explanation that Chen and Ritter's results for moderate-sized IPOs are consistent with explanations based on investment bankdifferentiating factors, the main hypothesis here is that for moderate-sized IPOs, bankdifferentiating factors are relevant for firms choosing banks to underwrite IPOs. Additional analysis provides some information on industries for which differentiation exists. Results are as follows.

For moderate-sized IPOs, the evidence for existence of the hypothesized bank-provided industry-based differentiation is not widespread.

For moderate-sized IPOs, over the period 1985-2003, about 12 percent (30 of 360) of four-digit SIC industries with at least two observations ${ }^{23}$ show evidence of relevance of bank-differentiating factors, as measured by a two-sided t-statistic of 2 or more. For the sub-periods 1985-87, 1988-94, 1995-98, and 1999-03, the comparable numbers are 12, 8, 10, and 4 percent, respectively. The numbers for these five experiments are shown Table 2, panel I, titled 'BASE CASE (SIC4)', row 6.

The distribution of SIC4 industries over IPO counts has a fat tail at the low end, and a long, narrow tail at the high end; that is, there are many industries with a relatively small number of IPOs, and there are a few industries with a relatively large number of IPOs. This can be seen in Figure 2, panel I. (For ease of reference, the x-axis in these panels is truncated at 50. Full data for panels I and II are given in Tables 2.1-2.5, (as discussed

\footnotetext{
${ }^{23}$ The differentiation index is not defined when the number of observations for an industry equals 1 , because in this case, $\mathrm{H}=1$. The results here are presented for cases where there are at least 2 observations for an industry.
} 
below as well,) and for panels III and IV in Table A.1 in the appendix.) The heavy line corresponds to the period 1985-03, and the different sub-periods show similar-shaped distributions. To understand the distributional effects on test results, four sets of robustness experiments are conducted - (1) averages of test results over various cutoffs of IPOs from a particular industry, (2) test results for a non-outlier sub-sample, (3) test results for SIC3 industries, and (4) test results for SIC2 industries.

The first robustness experiment considers SIC4 industries with at least $i$ IPOs, and at most $j$ IPOs, where $i$ and $j$ vary over the support of the distribution of IPO counts. For each such pair $(i, j)$, the proportion of industries in which differentiation exists is computed. The mean and median of all such tests are shown in Table 2, panel I, lines 7.1 (titled 'Robust (Mean)') and 7.2 (titled 'Robust (Median)'). (Additional details are presented below.) Over 1985-03, at the mean (line 7.1), differentiating factors are relevant for about 26 percent of industries, and at the median (line 7.2), for about 24 percent of industries. For the sub-periods 1985-87, 1988-94, 1995-98, and 1999-03, the comparable numbers for the mean are $27,15,19$, and 1 percent, respectively, and for the median are 25, 12, 15, and 0 percent, respectively. Thus, there do appear to be some distributional effects, but this experiment still yields absence of differentiation in a large proportion of industries.

Details for the numbers in lines 7.1 and 7.2 are presented in Tables 2.1-2.5. These tables can be read as follows. The first two columns of numbers present the distribution of industries (given in the first column) over IPO counts (given in the second column). For 
example, in Table 2.1, (for the period 1985-03,) there are 174 industries with 1 IPO, 96 industries with 2 IPOs, 47 with 3 IPOs, 30 with 4 IPOs, and so on. For convenience, each fraction in each of these tables is referenced by a pair $(i, j)$, where $i$ and $j$ vary over the support of the distribution of IPO counts, and over the words 'Mean' and 'Median'. The support of the distribution is shown in two places; in the second column, and in the first row of numbers. A fraction for pair $(i, j)$ gives the proportion of industries in which differentiation exists, conditional on an industry having at least $i+1$ IPOs and at most $j$ IPOs. For example, in Table 2.1, (for the period 1985-03,) entry $(1,353)$ is 0.12 ; that is, 12 percent of all industries with at least 2 IPOs and at most 353 IPOs (that is, the full sample for which the test can be computed) show existence of differentiation. Similarly, entry $(2,353)$ is 0.157 ; that is, about 16 percent of industries with at least 3 IPOs (that is, drop the 96 industries with 2 IPOs) and at most 353 IPOs show evidence of differentiation, and entry $(1,99)$ is 0.117 ; that is, about 12 percent of all industries with at least 2 IPOs and at most 99 IPOs (that is, drop the one largest industry) show evidence of differentiation. Similarly, entries on the cross-diagonal show the proportion of industries in which differentiation exists, conditional on an industry having exactly the number of column IPOs. For example, entry $(27,30)$ is 0.5 ; that is, one-half of industries with exactly 30 IPOs show existence of differentiation; and from the column for distribution of industries, it can be seen that there are exactly two such industries. Thus, one out of the two industries with 30 IPOs shows existence of differentiation. Similarly, entry $(26,27)$ shows that the one industry with 27 IPOs does not show evidence of differentiation, whereas entry $(25,26)$ shows that the one industry with 26 IPOs does show evidence of differentiation. These test results show, broadly, that the largest industries are potentially 
tending to move the results toward higher proportions of existence, and the smallest industries are potentially tending to move the result toward lower proportions. Consequently, outlier industries can potentially affect the test results.

To see the potential distributional impact, averages of these test results are presented in the rows and columns indexed 'Mean' and 'Median'. For example, in Table 2.1, (for the period 1985-03,) toward the end of the column indexed 353, the entry (Mean, 353) is 0.392; that is, if we keep dropping the smallest industries, and go all the way up to the largest industry (353 IPOs), at the mean, 39 percent of industries show evidence of differentiation, and at the median, entry (Median, 353), 33 percent of the industries show evidence of differentiation. Similarly, entry (Mean, 99) is 0.344 ; that is, if we consider industries with at most 99 IPOs (that is, drop the largest industry), and look at the impact on the test for existence by dropping smaller industries successively, then at the mean, 34 percent of the industries show evidence of differentiation, and at the median, entry (Median, 99), 31 percent of the industries show evidence of differentiation. In other words, the rows indexed 'Mean' and 'Median' present the "average" comparative statics of test results if we drop the "largest" industries. Looking across these rows shows that as we drop large industries, the test results decline a little initially, then increase till about the mid-size industries, and then decline as we keep dropping all but the smallest industries. Similarly, the columns indexed 'Mean' and 'Median' present the "average" comparative statics of test results if we drop the "smallest" industries. Looking down these columns shows that as we drop the smallest industries, the test results increase till about the mid-size industries, then decline a little for the larger industries, and they 
finally increase as we drop all but the 5 or 6 largest industries (consider entries in rows indexed 58-99, and columns indexed 'Mean' and 'Median'). Moreover, entries (Mean, 1) and (Median, 1) are the mean and median, respectively, of entries in the rows indexed 'Mean' and 'Median,' respectively. Similarly, entries (353, Mean) and (353, Median) are the mean and median, respectively, of entries in the columns indexed 'Mean' and 'Median,' respectively. Finally, entry (Mean, Mean) is 0.26 , and it is the average of entries (Mean, 1) and (353, Mean), and entry (Median, Median) is 0.239 , and it is the average of entries (Median, 1) and (353, Median), and these two numbers are presented in lines 7.1 and 7.2, respectively. Similar trends are present in the four sub-periods. (Confer Tables 2.2-2.5.) Thus, as mentioned above, this experiment shows a greater chance of differentiation existing in a handful of the largest industries, but this experiment confirms absence of differentiation in a large proportion of industries.

The second robustness experiment drops outlier industries at both ends of the distribution, and computes test results for a non-outlier sub-sample. The industries dropped are as follows. For the period 1985-03, industries with 4 or less IPOs are dropped, as are 6 of the 8 largest industries - five of these 6 industries are closely related by SIC code (737x and 738x, broadly, for computers and software), and the sixth is for semiconductors, and therefore, related to the other five. (Characteristics of industries with differentiation are discussed below.) More precisely, the six industries dropped are Prepackaged Software (SIC4 code 7372, with 353 IPOs), Semiconductors and Related Devices (3674, 99 IPOs), Computer Integrated Systems Design (7373, 91 IPOs), Information Retrieval Services (7375, 84 IPOs), Business Services, NEC (7389, 67 
IPOs), and Computer Programming Services (7371, 58 IPOs). (As mentioned above, if desired, distributions of industries by IPO counts can be viewed in Tables 2.1-2.5.) For the period 1985-87, industries with 2 or less IPOs are dropped, as are the two largest industries; Savings Institutions, Federally Chartered (6035, 23 IPOs), and Savings Institutions, Not Federally Chartered (6036, 18 IPOs). For the period 1988-94, industries with 3 or less IPOs are dropped, as are the four largest industries; Prepackaged Software (7372, 65 IPOs), Pharmaceutical Preparations (2834, 35 IPOs), Eating and Driking Places (5812, 28 IPOs), and Semiconductors and Related Devices (3674, 28 IPOs). For the period 1995-98, industries with 3 or less IPOs are dropped, as are the five largest industries; Prepackaged Software (7372, 143 IPOs), Computer Integrated Systems Design (7373, 43 IPOs), Computer Programming Services (7371, 42 IPOs), Semiconductors and Related Devices (3674, 36 IPOs), and Business Services, NEC (7389, 31 IPOs). For the period 1999-03, industries with 3 or less IPOs are dropped, as are the four largest industries; Prepackaged Software (7372, 132 IPOs), Information Retrieval Services (7375, 55 IPOs), Business Services, NEC (7389, 32 IPOs), and Semiconductors and Related Devices (3674, 31 IPOs). For this non-outlier sub-sample, the distribution of industries over IPO counts is shown in Figure 2, panel II. The heavy line corresponds to the period 1985-03. The other sub-periods show broadly similar distributions. ${ }^{24}$ The test results for this sub-sample are reported in Table 2, panel II, titled 'Non-Outlier Sub-Sample.' As shown in line 6, for 1985-2003, about 16 percent (19 of 121) of industries show evidence of relevance of bank-differentiating factors. For the sub-periods 1985-87, 1988-94, 1995-98, and 1999-03, the comparable numbers are 19, 7,

\footnotetext{
${ }^{24}$ The 1985-87 distribution is higher at 3, because industries with 3 IPOs are kept in this sub-period. This helps prevent the sub-sample from dropping a large proportion of the original sample. Confer the next footnote as well.
} 
12, and 0 percent, respectively. ${ }^{25}$ Therefore, this robustness experiment confirms absence of differentiation in a large proportion of industries.

The third robustness experiment looks at coarser industry classifications, by considering industries at the SIC3 level. Intuitively, it can be conjectured that SIC4 classifications may be too narrow for banks to specialize; for example, banks might not focus on Natural Gas Transmission (SIC4 4922) separately from Natural Gas Transmission and Distribution (SIC4 4923), or on Printed Circuit Boards (SIC4 3672) separately from Semiconductors and Related Devices (SIC 3674). For SIC3 classification, the distribution of industries over IPO counts is shown in Figure 2, panel III. The heavy line corresponds to the period 1985-03. As compared to the SIC4 classification, the SIC3 distribution for 1985-03 is noticeably lower at the smaller industry end, but for the sub-periods, the SIC3 distributions still show relatively elevated densities for the smaller industries. (Data are presented in Table A.1 in the appendix.) Test results for this experiment are reported in Table 2, panel III, titled 'SIC3.' As shown in line 6, for 1985-2003, about 13 percent (28 of 209) of industries show evidence of relevance of bank-differentiating factors. For the sub-periods 1985-87, 1988-94, 1995-98, and 1999-03, the comparable numbers are 6, 13, 11, and 14 percent, respectively. Once again, this robustness experiment confirms absence of differentiation in a large proportion of industries.

The fourth robustness experiment looks at still coarser industry classifications, by considering industries at the SIC2 level. This classification allows for broad industry

\footnotetext{
${ }^{25}$ For reference, another experiment was conducted with a sub-sample that deleted only the observations listed above for the period 1985-03. For that experiment, test results for 1985-03 are unchanged, of course. Moreover, test results for the sub-periods remained low; 12, 9, 10, and 4 percent, respectively.
} 
categories; for example, Electric Housewares and Fans (SIC4 3634) is in the same SIC2 class as Semiconductors and Related Devices (SIC4 3672). Similarly, Automobiles and Other Motor Vehicles (SIC4 5012), Furniture (SIC4 5021), Electrical Apparatus and Equipment Wiring (SIC4 5063), and Toys and Hobby Goods and Supplies (SIC4 5092) are all in the same SIC2 class. For SIC2 classification, the distribution of industries over IPO counts is shown in panel IV of Figure 2. The heavy line corresponds to the period 1985-03, and it looks considerably more uniform than the other cases. The sub-periods still show relatively elevated densities for the smaller industries, but these are noticeably lower as compared to SIC4 and SIC3. (Data for SIC2 are presented in Table A.1 in the appendix.) Test results for this experiment are reported in Table 2, panel IV, titled 'SIC2.' As shown in line 6, for 1985-2003, about 24 percent (15 of 63) of industries show evidence of relevance of bank-differentiating factors. For the sub-periods 1985-87, 198894, 1995-98, and 1999-03, the comparable numbers are 7, 20, 18, and 17 percent, respectively. Once again, this robustness experiment confirms absence of differentiation in a large proportion of industries.

Finally, to see the effect on test results of the high frequency of technology IPOs in the period 1998-2000, another three experiments (splitting the last two sub-periods into three sub-periods) were conducted. The results of these are in Table 2, panel V, titled 'ADJUSTED TIME PERIODS'. The percentages (row 6) for the three new sub-periods are a little lower than in the comparable two sub-periods in the base case, and overall, the results are similar to the base case. 
Additional details about test results for all SIC4 industries in the sample, and by frequency of IPOs are provided in Table A.2 in the appendix. As can be inferred from this table, there is no clear pattern that if differentiation exists for an industry then it necessarily exists for industries with similar SIC4 codes, or if differentiation exists for an industry in one period then it necessarily exists in other periods as well.

Taken together, these experiments show that other than in a handful of the very largest industries, there does not appear to be widespread existence of differentiation, contrary to hypothesis.

To explore characteristics of industries in which differentiation exists, and the extent to which differentiation exists, three of the above sets of experiments are considered in more detail; these are the ones based on SIC4, SIC3, and SIC2 classifications. In each case, the focus is on the period 1985-03.

For each of these cases, Figure 3 presents the differentiation index $(\delta)$ by industry code, conditional on existence of differentiation, and a corresponding histogram for the differentiation indices. In each case, industries in which differentiation exists are fairly diffused across the space of industries, showing no obvious pattern of existence, and for the bulk of industries, the differentiation index is less than 0.2 , as shown in the corresponding histogram. ${ }^{26}$ As shown in the bottom right panel, moving to broader

\footnotetext{
${ }^{26}$ For the SIC4 histogram, the bar for 0 includes 2 outliers with negative differentiation index (SIC4 2325 'Men's and Boys' Trousers and Slacks', Number of IPOs 2, Differentiation Index -0.59) and (SIC4 4822 'Telegraph and Other Message Communications', Number of IPOs 2, Differentiation Index -0.42), and the bar for 1 includes 1 outlier with differentiation index greater than 1 (SIC4 2331 'Women's, Misses', and
} 
industry classifications concentrates the distribution of differentiation indices toward the range 0-0.1. Some additional details for industries with differentiation are presented in Table s A.3 and A.4 in the appendix.

At the SIC2 level, (details are in Table A.4 in the appendix,) industries exhibiting differentiation appear to straddle relatively well-established industry segments (SIC2 13 'Oil and Gas Exploration'; SIC2 20 'Food and Kindred Products'; SIC2 42 'Motor Freight Transportation and Warehousing'; SIC2 58 'Eating and Drinking Places'; SIC2 59 'Miscellaneous Retail', SIC2 70 'Hotel, Rooming Houses, Camps, and Other Lodging Places'), relatively newer industry segments (SIC2 28 'Chemicals and Allied Products', which includes pharmaceutical preparations, and biological products; SIC2 48 ‘Communications'; SIC2 80 'Health Services'), and mixtures of established and newer industry segments (SIC36 'Electrical and Electronic Equipment', which includes household audio and video equipment, phonograph and prerecorded audio tapes, telephone and telegraph apparatus, printed circuit boards, and semiconductors; SIC2 73 'Business Services', which includes categories of computer and software, and also medical equipment rental and leasing, equipment rental and leasing, help supply services).

To provide a sense of the "average level" of differentiation that exists in a given time period, the weighted (by number of IPOs) average of differentiation indices is computed,

Juniors' Blouses', Number of IPOs 2, Differentiation Index 1.113). For the SIC3 histogram, the bar for 0 includes 1 outlier with negative differentiation index (SIC3 482, Number of IPOs 2, Differentiation Index 0.42). For clarity of comparison, these industries are not shown in the corresponding graph by SIC code. Full data are presented in Tables A.3 and A.4 in the appendix. 
for industries in which differentiation exists. ${ }^{27}$ This can be viewed as an aggregate measure of the level of differentiation that exists in a given time period. This measure is shown in Table 3. Notably, for each of the three SIC classifications considered here, this measure is small and is decreasing over time. ${ }^{28}$ Therefore, aggregate levels of differentiation do not appear to be increasing over time. This can be viewed as a slight extension of Chen and Ritter's puzzle; not only is price stability increasing over time, at least one measure of aggregate differentiation appears to be decreasing over time. Intuitively, it can be conjectured that the moderate-sized IPO industry, as a whole, appears to be moving toward lower levels of differentiation.

\section{Conclusion}

This paper presents some results on the relevance of investment bank-differentiating factors in firm choices of investment banks to underwrite IPOs. These results show that for moderate-sized IPOs, there is a greater chance that differentiation exists in a few of the very largest industries, but bank-differentiating factors over and above bank size are not significantly relevant for firms in a large proportion of industries. Moreover, at least one aggregate measure of differentiation is declining over time.

Notably, the analysis here does not investigate implicit collusion as a possible explanation. Chen and Ritter's puzzle is consistent with that explanation as well, and there is a growing literature that addresses that question.

\footnotetext{
${ }^{27}$ A similar measure cannot be constructed with great confidence at the industry level, because very few industries show existence of differentiation in all time periods.

${ }^{28}$ Not much confidence can be placed in one of these numbers; the number for SIC4 in the period 1999-03 is based on two small industries, one of which has a negative index. Details are in Tables A.3 and A.4 in the appendix.
} 
As mentioned above, this analysis can inquire if combinations of investment bankdifferentiating factors are important to firm choices, but it cannot investigate the importance of each such component. Consequently, a limitation of this analysis is that it does not shed light on the relevance of particular factors (such as underwriter reputation, quality of book-building, under-pricing, analyst coverage, over-allotment options, liquidity, and so on) on a firm's choice of underwriter. On the other hand, this analysis bypasses potential difficulties in measuring some of these factors. Additional work trying to understand the role of specific bank-differentiating factors would be very useful, both in trying to understand their direct effect on firm choices, and in trying to understand underwriter incentives regarding the provision of such differentiating factors. Such additional work could further shed light on the determination of IPO pricing in a broad sense that includes a joint determination of spreads, under-pricing, share allocation, aftermarket price stabilization, and other bank-differentiating factors. This can help explain more completely Chen and Ritter's seven percent puzzle. 


\section{References}

Anand, B. N. and A. Galetovic, 2002, Investment Banking and Security Market Development: Why is Chile different from the United States? Working paper, Harvard University

Anand, B.N. and A. Galetovic, 2000, Relationships, Competition, and the Structure of Investment Banking Markets, Working paper, Harvard University

Beatty, R. and Jay Ritter, 1986, Investment banking, reputation, and the underpricing of initial public offerings, Journal of Financial Economics, 15, 213-232

Benveniste, L. and P. A. Spindt, 1989, How Investment Bankers Determine the Offer Price and Allocation of New Issues, Journal of Financial Economics, 24, 343-361

Benveniste, L. M., A. Ljungqvist, W. J. Wilhelm Jr., and X. Yu, 2003, Information externalities and the role of underwriters in primary equity markets, Journal of Finance, 58(2), 577-608

Benveniste, L. M., W. Busaba, and W. J. Wilhelm, 2002, Information externalities and the role of underwriters in primary equity markets, Journal of Financial Intermediation, 11, 61-86

Booth, J., and R. Smith, 1986, Capital raising, underwriting, and the certification hypothesis, Journal of Financial Economics 15, 261-281

Carter, R., F. Dark, and A. Singh, 1998, Underwriter reputation, initial returns, and the long-run performance of IPO stocks, Journal of Finance, 53(February), 285-311

Carter, R., and S. Manaster, 1990, Initial public offerings and underwriter reputation, Journal of Finance 45 (September), 1045-1067

Chemmanur, T., and P. Fulghieri, 1994, Investment bank reputation, information production, and financial intermediation, Journal of Finance 49, 59-79

Chen, H-C, 1998, Competition and Collusion in the IPO Market, Working Paper, University of Florida

Chen, H-C, and J.R. Ritter, 2000, The seven percent solution, Journal of Finance 55, 1105-1131

Christie, W., and P. Schultz, 1994, Why do Nasdaq market makers avoid odd-eighth quotes? Journal of Finance 49, 1813-1840

Christie, W., J. Harris, and P. Schultz, 1994, Why did Nasdaq market makers stop avoiding odd-eighth quotes? Journal of Finance 49, 1841-1860 
Dunbar, C.G., 2000, Factors affecting investment bank initial public offering market share, Journal of Financial Economics 55, 3-41

Dutta, P., and A. Madhavan, 1997, Competition and collusion in dealer markets, Journal of Finance 52, 245-276

Eccles, R.G., and D.B. Crane, 1988, Doing Deals, Harvard Business School, Cambridge

Ellison, G., and E Glaeser, 1997, Geographic Concentration in U.S. Manufacturing Industries: A Dartboard Approach, Journal of Political Economy 105, 889-927

Gande, A., M. Puri, and A. Saunders, 1999, Bank entry, competition, and the market for corporate securities underwriting, Journal of Financial Economics 54, 165-195

Gordon, B. R., 2003, The Seven Percent Illusion? Working Paper, Carnegie Mellon University

Hansen, R.S., 2001, Do investment banks compete in IPOs? The advent of the "7\% plus contract, Journal of Financial Economics, 59, 313-346

James C., 1992, Relationship-specific assets and the pricing of underwriting services, Journal of Finance 47, 1865-1885

Krigman, L., W. H. Shaw, and K. L. Womack, 2001, Why do firms switch underwriters? Journal of Financial Economics 60, 245-284

Logue, D. E., R. J. Rogalski, J. K. Seward, and L. Foster-Johnson, 2002, What is special about the roles of underwriter reputation and market activities in initial public offerings?, Journal of Business, 75 (2), 213-243

Lowenstein, Roger, 1997, Street's incredible unshrinking spread, The Wall Street Journal, April 10, C1

Lowry, Michelle and G. William Schwert, 2002, IPO market cycles: Bubbles or sequential learning? Journal of Finance 57, 1171-1200

Ljungqvist, A., and W. J. Wilhelm, Jr., 1999, The seven percent solution? An international perspective on underwriting spreads, Working paper, Said Business School

Ritter, Jay, and Ivo Welch, 2002, A Review of IPO Activity, Pricing, and Allocations, Journal of Finance, 57 (4), 1795-1828

Rotemberg, J., and G. Saloner, 1986, A super-game theoretical model of price wars during booms, American Economic Review 76, 390-407 
Figure 1. Gross Spreads: Moderate-Sized IPOs

(Extension of Chen and Ritter, Figure 1.)

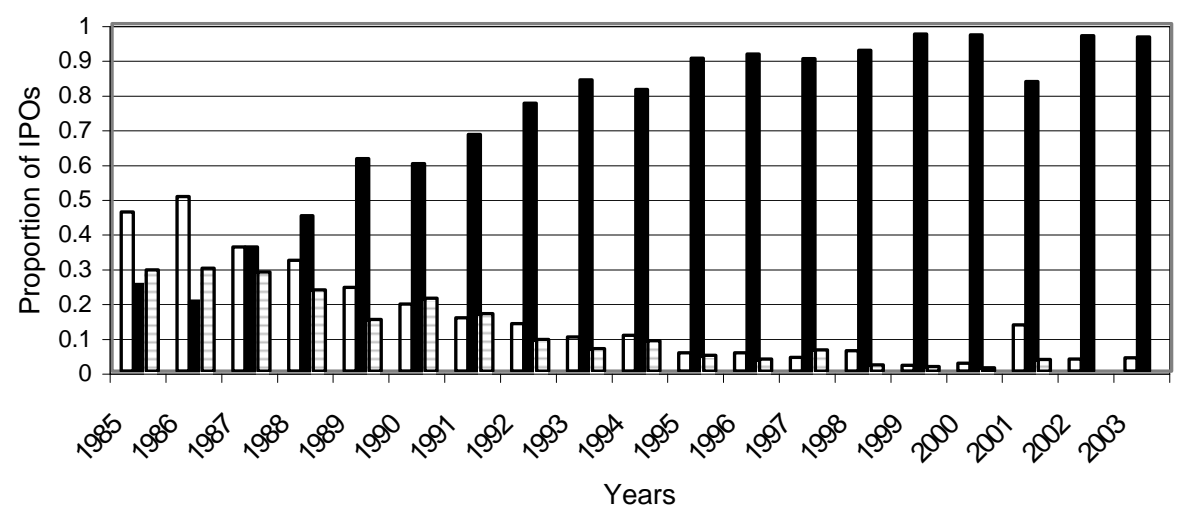

$\square$ Below $7 \%$ At $7 \%$ above $7 \%$ 
"Kulkarni, Kedar and Tarun Sabarwal (2007): “To What Extent Are Investment Bank-Differentiating Factors Relevant For Firms Floating Moderate-Sized IPOs?” Annals of Finance, 3(3), July, 297-327. Publisher's official version: http://dx.doi.org/10.1007/s10436-006-0054-y.Open Access version: http://kuscholarworks.ku.edu/dspace/.

Table 1: Moderate-Sized IPOs (\$20-\$80 million, 1997 CPI dollars)

\begin{tabular}{|c|c|c|c|c|c|c|c|}
\hline & \multicolumn{4}{|c|}{ Number } & \multicolumn{3}{|c|}{ Proportion } \\
\hline Period & Below 7\% & At 7\% & Above $7 \%$ & Total & Below 7\% & At 7\% & Above $7 \%$ \\
\hline $1985-87$ & 173 & 104 & 114 & 391 & 0.442 & 0.266 & 0.292 \\
\hline 1988-94 & 138 & 734 & 111 & 983 & 0.140 & 0.747 & 0.113 \\
\hline $1995-98$ & 57 & 1028 & 47 & 1132 & 0.050 & 0.908 & 0.042 \\
\hline 1999-03 & 16 & 583 & 7 & 606 & 0.026 & 0.962 & 0.012 \\
\hline Total & 384 & 2449 & 279 & 3112 & 0.123 & 0.787 & 0.090 \\
\hline
\end{tabular}




\section{Table 2. Existence of Differentiation}

\begin{tabular}{lrrrrr} 
& $1985-03$ & $1985-87$ & $1988-94$ & $1995-98$ & $1999-03$ \\
I. BASE CASE (SIC4) & & & & & \\
\hline Number of IPOs & 3101 & 384 & 982 & 1129 & 606 \\
2 Number of Banks & 197 & 54 & 91 & 108 & 83 \\
3 Number of Industries & 474 & 185 & 304 & 276 & 118 \\
4 Industries with >1 obs & 300 & 68 & 167 & 146 & 54 \\
5 Differentiation Exists (N) & 36 & 8 & 14 & 14 & \\
6 Differentiation Exists (Prop.) & 0.120 & 0.118 & 0.084 & 0.096 & 0.037 \\
7 Differentiation Exists (Robust) & & & & & \\
7.1 Robust (Mean) & 0.260 & 0.271 & 0.153 & 0.186 & 0.011 \\
7.2 Robust (Median) & 0.239 & 0.247 & 0.118 & 0.153 & 0.000
\end{tabular}

\section{NON-OUTLIER SUB-SAMPLE}

1 Number of IPOs

2 Number of Banks

$\begin{array}{rrrrr}1722 & 168 & 439 & 521 & 228 \\ 164 & 33 & 69 & 81 & 48 \\ 121 & 37 & 57 & 61 & 24 \\ 121 & 37 & 57 & 61 & 24 \\ 19 & 7 & 4 & 7 & 0 \\ 0.157 & 0.189 & 0.070 & 0.115 & 0.000\end{array}$

3 Number of Industries

4 Industries with $>1$ obs

5 Differentiation Exists $(\mathrm{N})$

6 Differentiation Exists (Prop.)

\section{SIC3}

3 Number of Industries

4 Industries with $>1$ obs

5 Differentiation Exists ( $\mathrm{N}$ )

6 Differentiation Exists (Prop.)

$\begin{array}{rrrrr}262 & 137 & 193 & 174 & 85 \\ 209 & 68 & 126 & 115 & 36 \\ 28 & 4 & 16 & 13 & 5 \\ 0.134 & 0.059 & 0.127 & 0.113 & 0.139\end{array}$

\section{SIC2}

3 Number of Industries

4 Industries with $>1$ obs

5 Differentiation Exists $(\mathrm{N})$

6 Differentiation Exists (Prop.)

$\begin{array}{rrrrr}67 & 57 & 64 & 59 & 38 \\ 63 & 43 & 55 & 56 & 24 \\ 15 & 3 & 11 & 10 & 4 \\ 0.238 & 0.070 & 0.200 & 0.179 & 0.167\end{array}$

\section{ADJUSTED TIME PERIODS}

$\begin{array}{lllllll}1985-03 & 1985-87 & 1988-94 & 1995-97 & 1998-00 & 2001-03\end{array}$

1 Number of IPOs

$$
85-87
$$

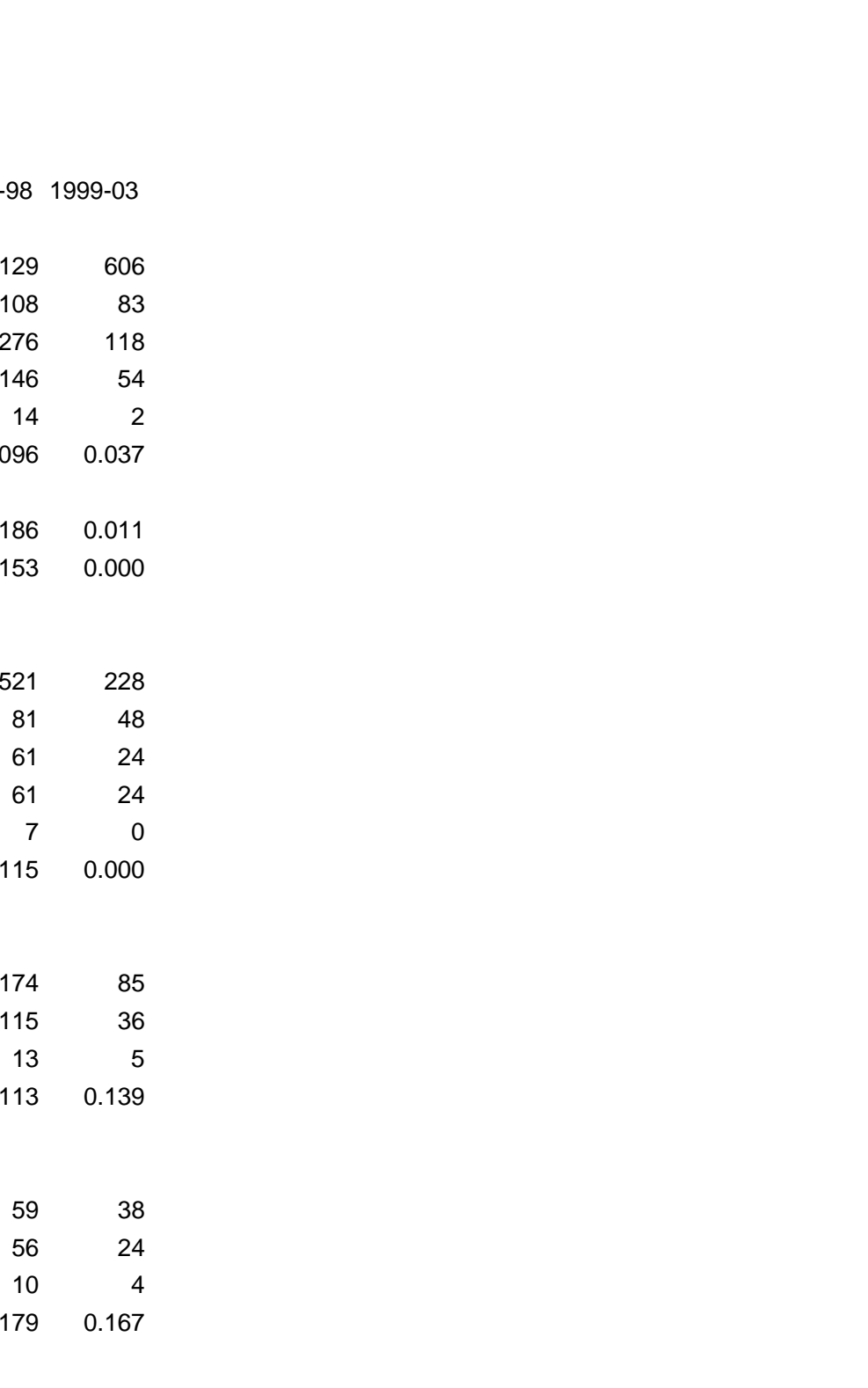

2 Number of Banks

3101

384

982

960

690

3 Number of Industries

197
474

54
185

91
304

100

90

85

4 Industries with $>1$ obs

5 Differentiation Exists ( $N$ )

6 Differentiation Exists (Prop.)

474
300
36
0.120

167

253

148

$127 \quad 67$

$8 \quad 14$

$0.118 \quad 0.084$

0.079

0.060

38

Note.

Rows 1 and 2 of panels III and IV are the same as in panel I. 
"Kulkarni, Kedar and Tarun Sabarwal (2007): "To What Extent Are Investment Bank-Differentiating Factors Relevant For Firms Floating Moderate-Sized IPOs?"

\section{Figure 2. Distribution of Industries by IPO Counts}
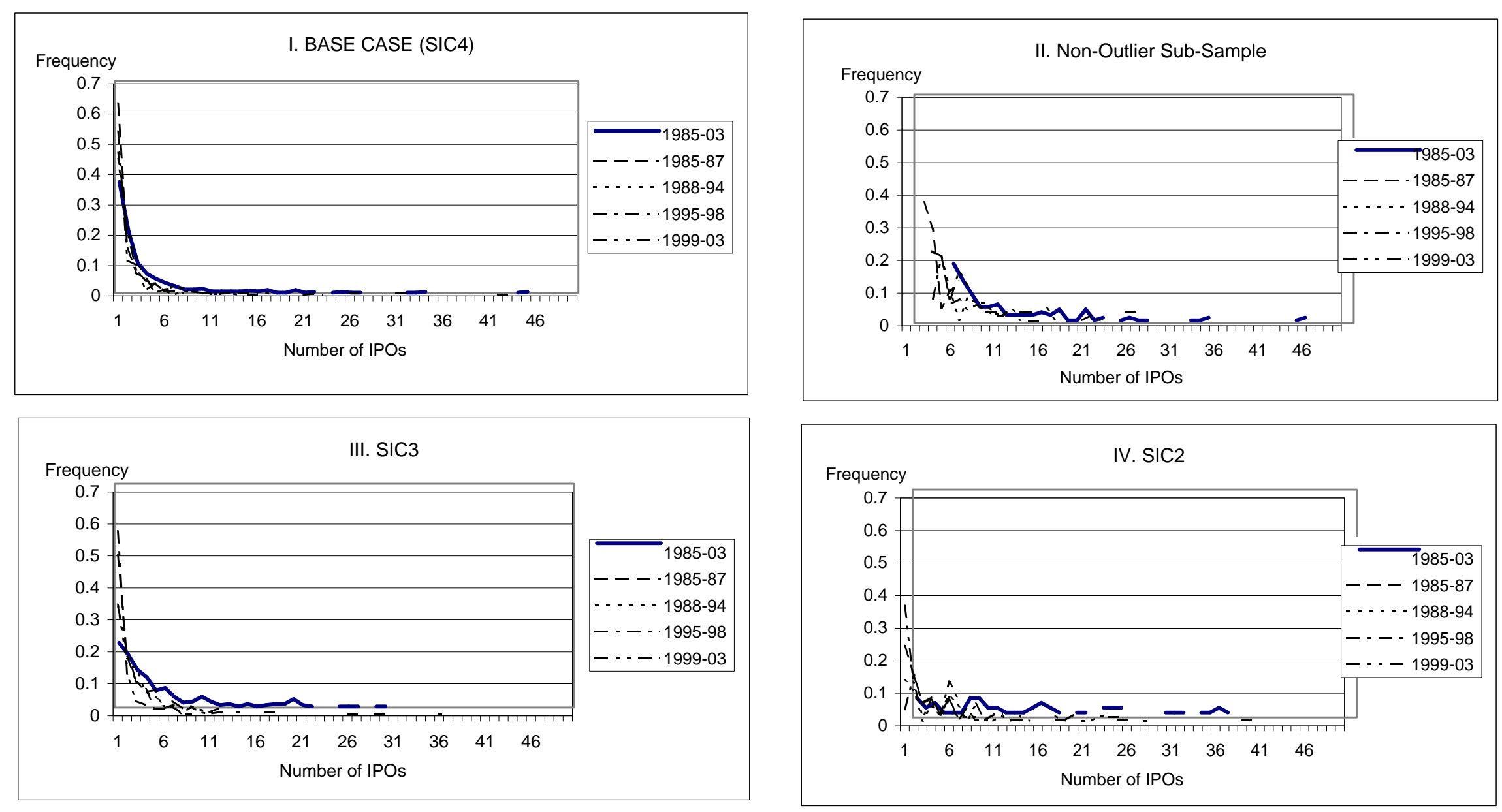
Table 2.1. Test Results by Various Cutoffs of IPO Counts (1985-03)

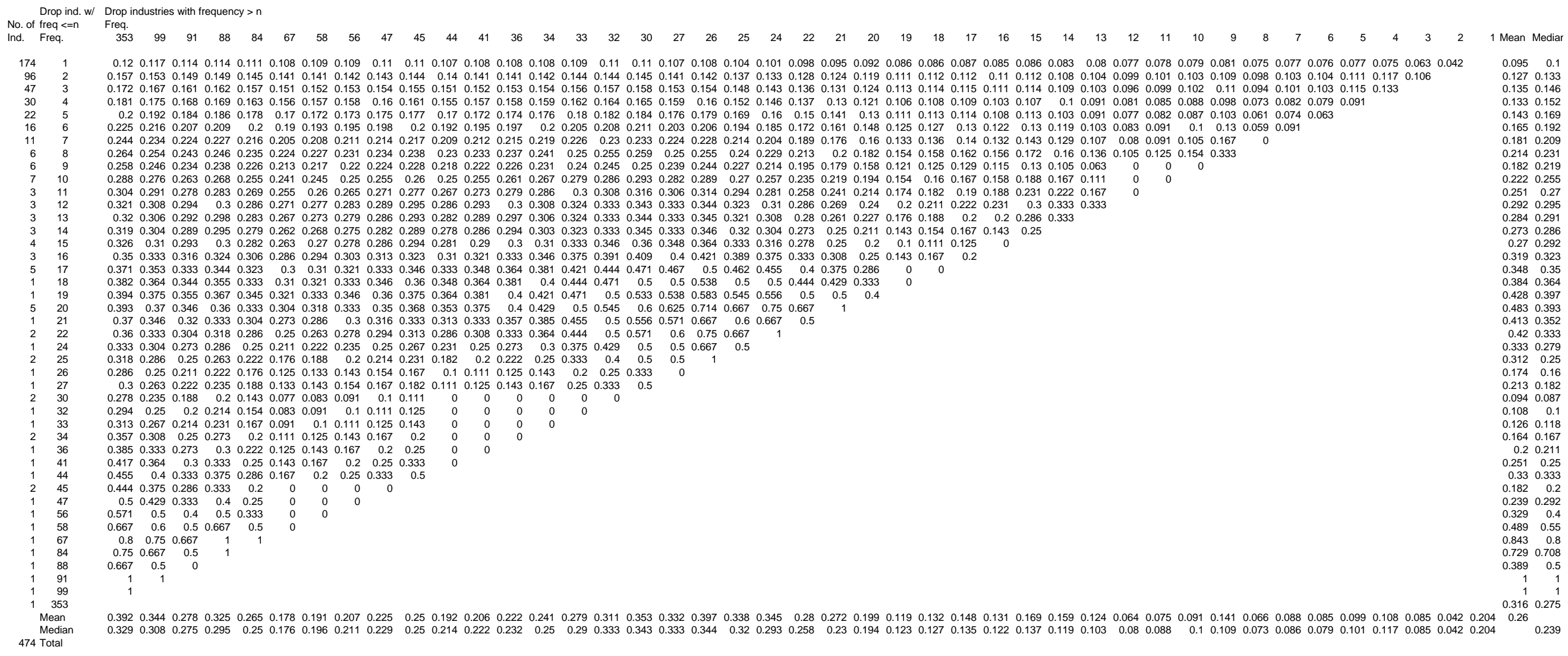


"Kulkarni, Kedar and Tarun Sabarwal (2007): "To What Extent Are Investment Bank-Differentiating Factors Relevant For Firms Floating Moderate-Sized IPOs?"

Annals of Finance, 3(3), July, 297-327. Publisher's official version: http://dx.doi.org/10.1007/s10436-006-0054-y.Open Access version: http://kuscholarworks.ku.edu/dspace/.

Table 2.2. Test Results by Various Cutoffs of IPO Counts (1985-87)

\begin{tabular}{|c|c|c|c|c|c|c|c|c|c|c|}
\hline \multirow{2}{*}{\multicolumn{2}{|c|}{$\begin{array}{l}\text { Drop ind. w/ } \\
\text { No. of freq <=n } \\
\text { Ind. Freq. }\end{array}$}} & \multicolumn{9}{|c|}{$\begin{array}{l}\text { Drop industries with frequency }>n \\
\text { Frea }\end{array}$} \\
\hline & & $23 \quad 18$ & 13 & 7 & 6 & 5 & 4 & 3 & 2 & 1 Mean Mediar \\
\hline & & $0.118 \quad 0.119$ & $0.106 \mathrm{c}$ & 0.092 & $0.083 \mathrm{C}-\mathrm{c}=\mathrm{c} \mathrm{c}$ & & & 0.07 & 0 & 0.078 \\
\hline 29 & 2 & $0.205 \quad 0.211$ & 0.189 & 0.167 & 0.161 & 0.111 & 0.120 & 0.214 & & 172 \\
\hline 14 & 3 & 0.20 .208 & $0.174 \mathrm{c} \quad \mathrm{C}$ & $0.136 \mathrm{c}$ & 0.118 & 0 & & & & 0.119 \\
\hline 11 & 4 & $0.357 \quad 0.385$ & $0.333 \mathrm{c}$ & 0.273 & 0.333 & 0 & & & & 0.28 \\
\hline 2 & 5 & $0.417 \quad 0.455$ & $0.4 \mathrm{C}$ & 0.333 & 0.5 & & & & & 421 \\
\hline 4 & 6 & $0.375 \quad 0.429$ & 0.333 & 0.2 & & & & & & $0.334 \quad 0.354$ \\
\hline 5 & 7 & 0.667 & 1 & & & & & & & 0.889 \\
\hline 1 & 13 & 0.5 & & & & & & & & $0.75 \quad 0.75$ \\
\hline & 18 & 0 & & & & & & & & 0 \\
\hline & 23 & & & & & & & & & $0.338 \quad 0.333$ \\
\hline & Mean & 0.3150 .476 & 0.362 & 0.2 & $0.239 \mathrm{C}$ & 0.041 & $\begin{array}{lll}0.059 & 0\end{array}$ & & & 040.271 \\
\hline & & $0.357 \quad 0.407$ & $0.333 \mathrm{C}-\mathrm{s}$ & $0.183 \mathrm{C}$ & $0.161 \mathrm{C}$ & 0.027 & 0.0560 & & & 0.247 \\
\hline
\end{tabular}


"Kulkarni, Kedar and Tarun Sabarwal (2007): “To What Extent Are Investment Bank-Differentiating Factors Relevant For Firms Floating Moderate-Sized IPOs?"

Annals of Finance, 3(3), July, 297-327. Publisher's official version: http://dx.doi.org/10.1007/s10436-006-0054-y.Open Access version: http://kuscholarworks.ku.edu/dspace/.

\section{Table 2.3. Test Results by Various Cutoffs of IPO Counts (1988-94)}

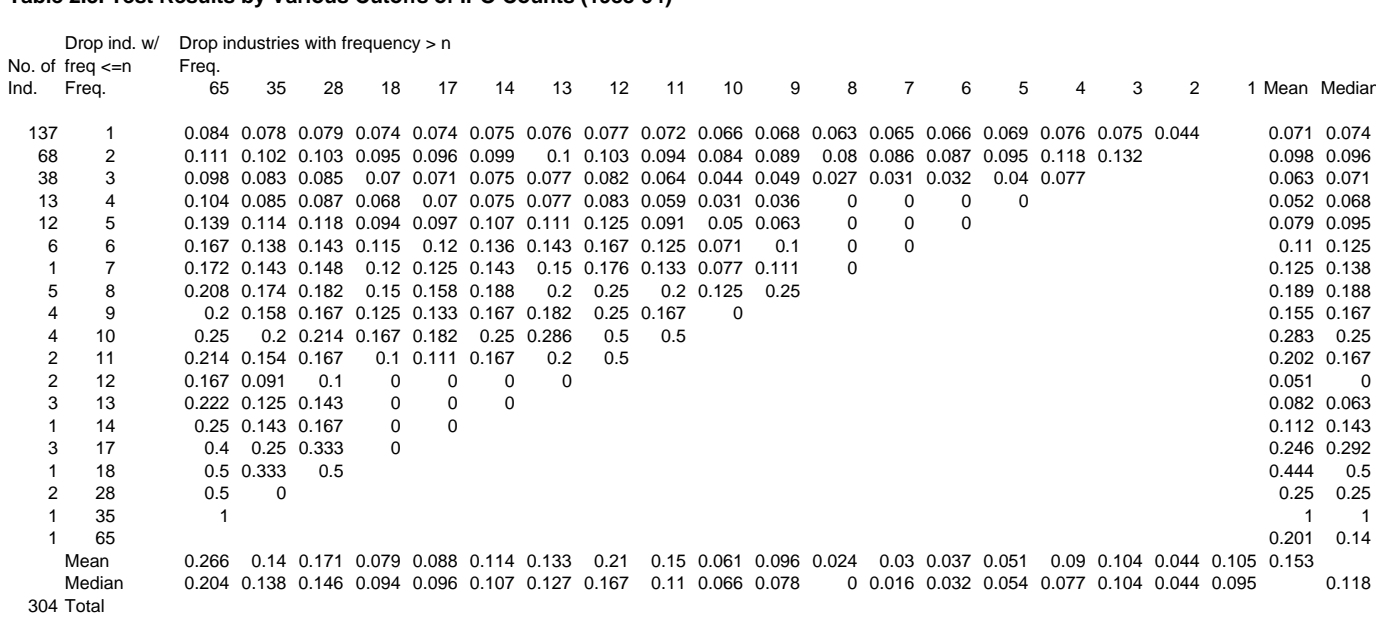


"Kulkarni, Kedar and Tarun Sabarwal (2007): “To What Extent Are Investment Bank-Differentiating Factors Relevant For Firms Floating Moderate-Sized IPOs?"

Annals of Finance, 3(3), July, 297-327. Publisher's official version: http://dx.doi.org/10.1007/s10436-006-0054-y.Open Access version: http://kuscholarworks.ku.edu/dspace/.

\section{Table 2.4. Test Results by Various Cutoffs of IPO Counts (1995-98)}

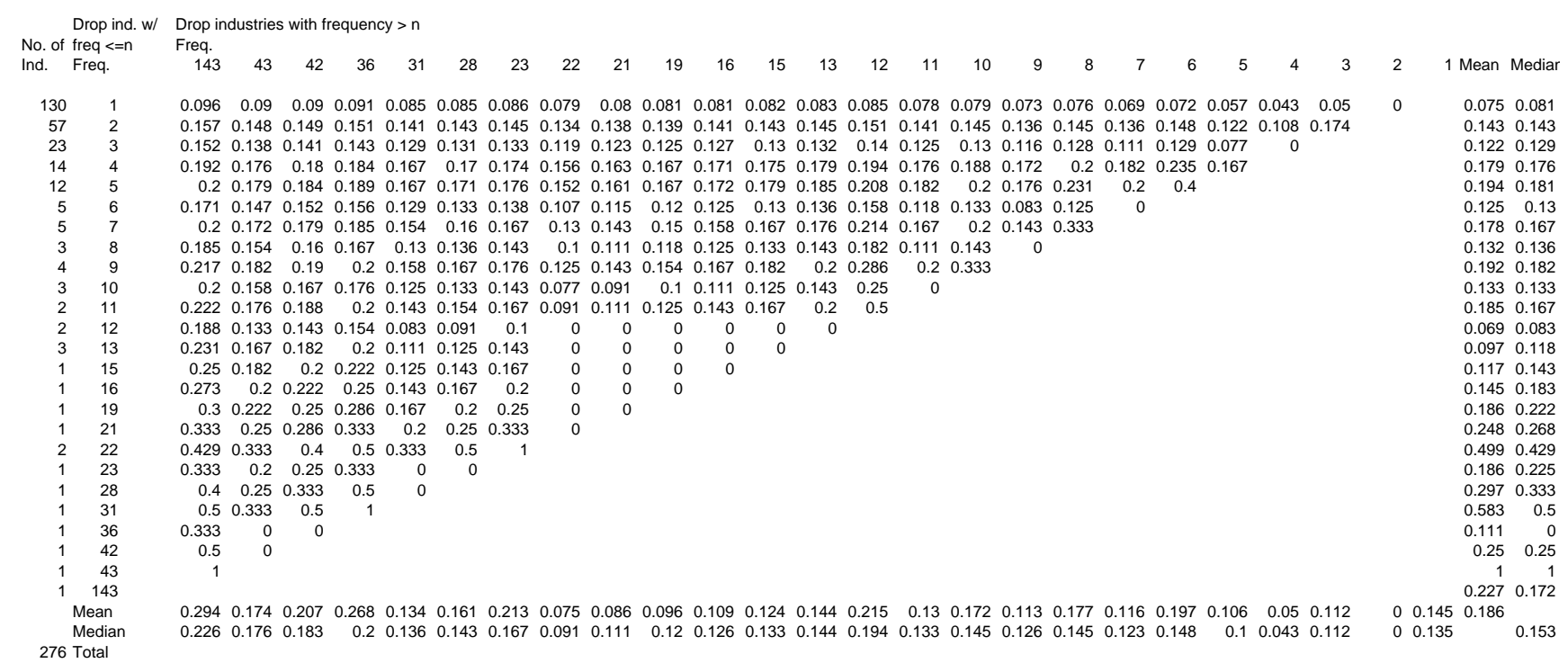


Figure 3. Characteristics of Industries with Differentiation
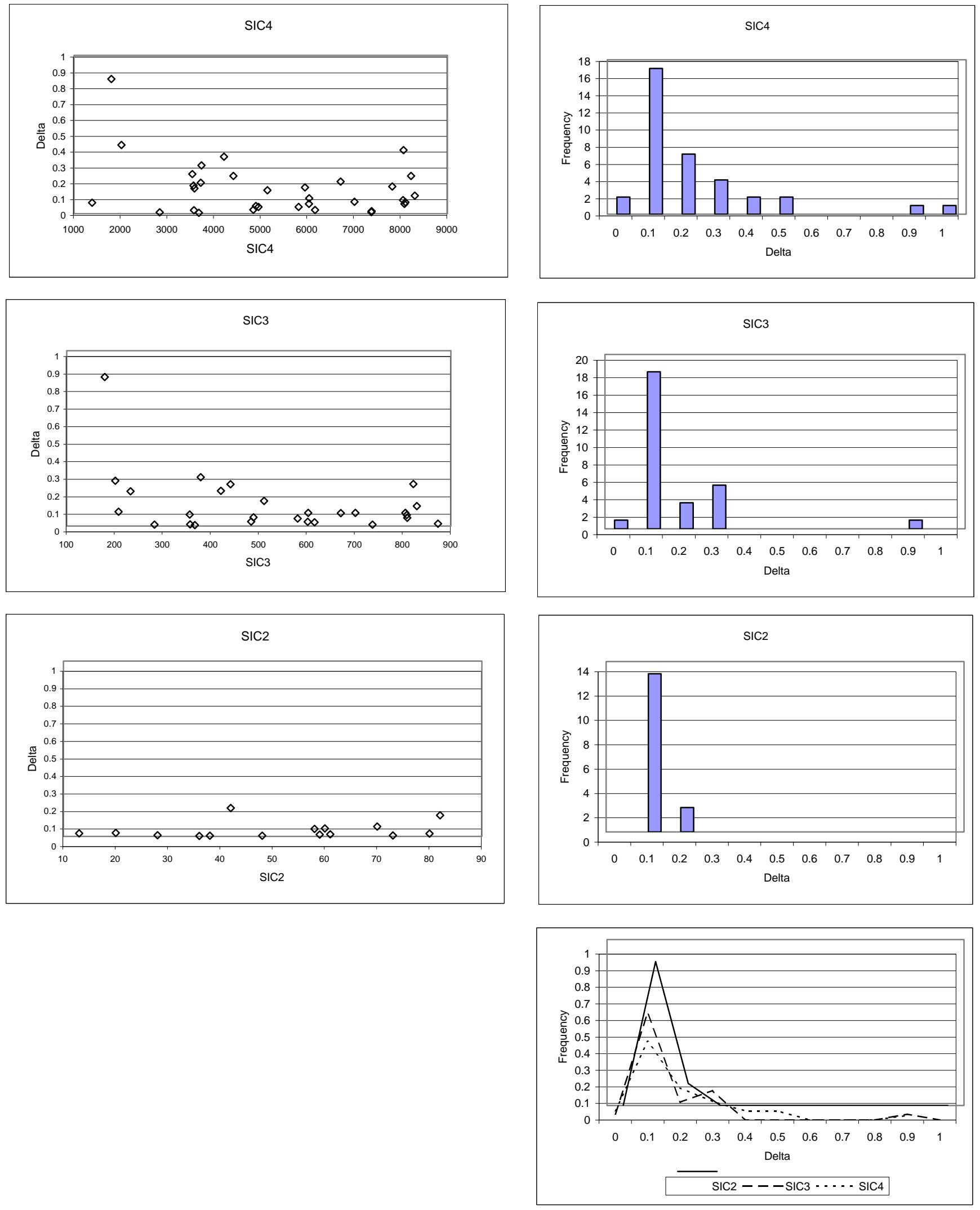


\section{Table 3. Average Levels of Differentiation}

1985-03 $1985-87 \quad 1988-94 \quad 1995-98 \quad 1999-03$

Differentiation Index (Wt. Average)

SIC4

SIC3

SIC2

$\begin{array}{lllll}0.045 & 0.207 & 0.150 & 0.079 & 0.075 \\ 0.026 & 0.089 & 0.105 & 0.044 & 0.009 \\ 0.013 & 0.065 & 0.057 & 0.022 & 0.010\end{array}$


"Kulkarni, Kedar and Tarun Sabarwal (2007): “To What Extent Are Investment Bank-Differentiating Factors Relevant For Firms Floating Moderate-Sized IPOs?"

Annals of Finance, 3(3), July, 297-327. Publisher's official version: http://dx.doi.org/10.1007/s10436-006-0054-y.Open Access version: http://kuscholarworks.ku.edu/dspace/.

\section{Appendix}

SIC3
$1985-03$
$\operatorname{pos}(n)$

$\begin{array}{ll}1985-03 & 1985-87 \\ \operatorname{ipos}(n) \text { freq }(n) \text { prop } & \text { ipos(n) freq }(n)\end{array}$

\begin{tabular}{|c|c|c|c|c|}
\hline 53 & 0.2023 & 1 & 69 & 0.5036 \\
\hline 43 & 0.1641 & 2 & 25 & 0.1825 \\
\hline 31 & 0.1183 & 3 & 15 & 0.1095 \\
\hline 25 & 0.0954 & 4 & 12 & 0.0876 \\
\hline 14 & 0.0534 & 5 & 3 & 0.0219 \\
\hline 16 & 0.0611 & 6 & 3 & 0.0219 \\
\hline 9 & 0.0344 & 7 & 4 & 0.0292 \\
\hline 4 & 0.0153 & 8 & 1 & 0.0073 \\
\hline 5 & 0.0191 & 9 & 1 & 0.0073 \\
\hline 9 & 0.0344 & 11 & 1 & 0.0073 \\
\hline 5 & 0.0191 & 17 & 1 & 0.0073 \\
\hline 2 & 0.0076 & 25 & 1 & 0.0073 \\
\hline 3 & 0.0115 & 41 & 1 & 0.0073 \\
\hline 1 & 0.0038 & & & \\
\hline 3 & 0.0115 & & & \\
\hline 1 & 0.0038 & & & \\
\hline 2 & 0.0076 & & & \\
\hline 3 & 0.0115 & & & \\
\hline 3 & 0.0115 & & & \\
\hline 7 & 0.0267 & & & \\
\hline 2 & 0.0076 & & & \\
\hline 1 & 0.0038 & & & \\
\hline 1 & 0.0038 & & & \\
\hline 1 & 0.0038 & & & \\
\hline 1 & 0.0038 & & & \\
\hline 1 & 0.0038 & & & \\
\hline 1 & 0.0038 & & & \\
\hline 1 & 0.0038 & & & \\
\hline 2 & 0.0076 & & & \\
\hline 1 & 0.0038 & & & \\
\hline 1 & 0.0038 & & & \\
\hline 2 & 0.0076 & & & \\
\hline 1 & 0.0038 & & & \\
\hline 1 & 0.0038 & & & \\
\hline 1 & 0.0038 & & & \\
\hline 1 & 0.0038 & & & \\
\hline 1 & 0.0038 & & & \\
\hline 1 & 0.0038 & & & \\
\hline 1 & 0.0038 & & & \\
\hline 1 & 0.0038 & & & \\
\hline
\end{tabular}

$1988-94$
$\operatorname{ipos}(n)$ freq

$\begin{array}{ll}1995-98 & 1999-03 \\ i \operatorname{ipos}(n) \text { freq (n) prop } & \text { ipos(n) freq (n) prop }\end{array}$

\section{ies by IPOs Counts}

SIC2 $1985-03$

1985-87

1988-94

$1995-98$

1999-03

$\operatorname{ipos}(n)$ freq $(n)$ prop ipos(n) freq (n) prop ipos $(n)$ freq $(n)$ prop ipos(n) freq (n) prop ipos(n) freq (n) prop

\begin{tabular}{|c|c|c|c|c|c|}
\hline $\begin{array}{ll}67 & 0.3472\end{array}$ & 1 & $\begin{array}{ll}59 & 0.3391\end{array}$ & 1 & 49 & 0.5765 \\
\hline 310.1606 & 2 & $\begin{array}{ll}35 & 0.2011\end{array}$ & 2 & 11 & 0.1294 \\
\hline 290.1503 & 3 & 190.1092 & 3 & 4 & 0.0471 \\
\hline $15 \quad 0.0777$ & 4 & $13 \quad 0.0747$ & 4 & 3 & 0.0353 \\
\hline $12 \quad 0.0622$ & 5 & $14 \quad 0.0805$ & 5 & 2 & 0.0235 \\
\hline $\begin{array}{ll}6 & 0.0311\end{array}$ & 6 & $\begin{array}{ll}4 & 0.023\end{array}$ & 7 & 4 & 0.0471 \\
\hline $\begin{array}{ll}6 & 0.0311\end{array}$ & 7 & $\begin{array}{ll}6 & 0.0345\end{array}$ & 8 & 2 & 0.0235 \\
\hline $\begin{array}{ll}6 & 0.0311\end{array}$ & 8 & 10.0057 & 11 & 1 & 0.0118 \\
\hline 40.0207 & 9 & $\begin{array}{ll}5 & 0.0287\end{array}$ & 12 & 2 & 0.0235 \\
\hline 20.0104 & 10 & 20.0115 & 17 & 1 & 0.0118 \\
\hline 20.0104 & 11 & 10.0057 & 18 & 1 & 0.0118 \\
\hline 20.0104 & 12 & 20.0115 & 25 & 1 & 0.0118 \\
\hline 20.0104 & 13 & 20.0115 & 32 & 1 & 0.0118 \\
\hline 20.0104 & 18 & $\begin{array}{ll}1 & 0.0057\end{array}$ & 37 & 1 & 0.0118 \\
\hline 10.0052 & 21 & 10.0057 & 45 & 1 & 0.0118 \\
\hline 10.0052 & 26 & $\begin{array}{ll}1 & 0.0057\end{array}$ & 248 & 1 & 0.0118 \\
\hline 10.0052 & 27 & 10.0057 & & & \\
\hline 10.0052 & 29 & $\begin{array}{ll}1 & 0.0057\end{array}$ & & & \\
\hline 0.0052 & 30 & 10.0057 & & & \\
\hline 10.0052 & 32 & 10.0057 & & & \\
\hline 10.0052 & 45 & 10.0057 & & & \\
\hline & 56 & 10.0057 & & & \\
\hline & 58 & 10.0057 & & & \\
\hline & 279 & $\begin{array}{ll}1 & 0.0057\end{array}$ & & & \\
\hline
\end{tabular}

\begin{tabular}{ll}
4 & 0.0597 \\
2 & 0.0299 \\
3 & 0.0448 \\
1 & 0.0149 \\
1 & 0.0149 \\
1 & 0.0149 \\
4 & 0.0597 \\
4 & 0.0597 \\
2 & 0.0299 \\
2 & 0.0299 \\
1 & 0.0149 \\
1 & 0.0149 \\
1 & 0.0149 \\
2 & 0.0299 \\
3 & 0.0448 \\
2 & 0.0299 \\
1 & 0.0149 \\
1 & 0.0149 \\
1 & 0.0149 \\
2 & 0.0299 \\
2 & 0.0299 \\
2 & 0.0299 \\
1 & 0.0149 \\
1 & 0.0149 \\
1 & 0.0149 \\
1 & 0.0149 \\
1 & 0.0149 \\
2 & 0.0299 \\
1 & 0.0149 \\
1 & 0.0149 \\
1 & 0.0149 \\
2 & 0.0299 \\
1 & 0.0149 \\
1 & 0.0149 \\
1 & 0.0149 \\
1 & 0.0149 \\
1 & 0.0149 \\
1 & 0.0149 \\
1 & 0.0149 \\
1 & 0.0149 \\
1 & 0.0149 \\
1 & 0.0149 \\
1 & 0.0149 \\
1 & 0.0149 \\
& \\
\hline
\end{tabular} 90.1579 50.0877 50.0877

$\begin{array}{ll}2 & 0.0351 \\ 5 & 0.0877 \\ 1 & 0.0175\end{array}$

$\begin{array}{llll}5 & 0.0877 \\ 1 & 0.0175\end{array}$

30.0526

$\begin{array}{ll}3 & 0.0526 \\ 1 & 0.0175\end{array}$

10.0175

$\begin{array}{lll}2 & 0.0351\end{array}$

20.0351

$\begin{array}{lll}1 & 0.0175\end{array}$

$\begin{array}{ll}2 & 0.0351 \\ 1 & 0.0175\end{array}$

$\begin{array}{ll}1 & 0.0175 \\ 1 & 0.0175\end{array}$

$\begin{array}{ll}1 & 0.0175 \\ 1 & 0.0175 \\ 1 & 0.0175\end{array}$

10.0175

10.0175

\section{$\begin{array}{ll}9 & 0.1406 \\ 7 & 0.1094\end{array}$}

$\begin{array}{ll}7 & 0.1094 \\ 1 & 0.0156\end{array}$

$\begin{array}{ll}1 & 0.0156 \\ 4 & 0.0625\end{array}$

$\begin{array}{ll}3 & 0.0469\end{array}$

$\begin{array}{ll}6 & 0.0938 \\ 4 & 0.0625\end{array}$

$\begin{array}{ll}4 & 0.0625 \\ 1 & 0.0156\end{array}$

$4 \quad 0.0625$

$\begin{array}{ll}4 & 0.0625 \\ 1 & 0.0156\end{array}$

20.0313

10.0156

$\begin{array}{ll}2 & 0.0313 \\ 1 & 0.0156\end{array}$

$\begin{array}{ll}1 & 0.0156 \\ 2 & 0.0313\end{array}$

$\begin{array}{ll}2 & 0.0313 \\ 1 & 0.0156\end{array}$

$\begin{array}{ll}1 & 0.0156 \\ 1 & 0.0156\end{array}$

$\begin{array}{lll}1 & 0.0156\end{array}$

20.0313

$\begin{array}{ll}2 & 0.0313 \\ 1 & 0.0156\end{array}$

$\begin{array}{ll}1 & 0.0156 \\ 1 & 0.0156\end{array}$

$\begin{array}{ll}1 & 0.0156 \\ 1 & 0.0156\end{array}$

$\begin{array}{ll}1 & 0.0156 \\ 1 & 0.0156\end{array}$

10.0156

10.0156

$\begin{array}{ll}1 & 0.0156 \\ 1 & 0.0156\end{array}$

$\begin{array}{ll}1 & 0.0156 \\ 1 & 0.0156\end{array}$

$1 \quad 30.0508$ $\begin{array}{lllll}4 & 0.0678 & 3 & 1 & 0.0263\end{array}$ $\begin{array}{lllll}5 & 0.0847 & 4 & 3 & 0.0789\end{array}$

Note: Distribution of SIC4 industries by IPO counts is available in Tables 2.1-2.5. 
"Kulkarni, Kedar and Tarun Sabarwal (2007): “To What Extent Are Investment Bank-Differentiating Factors Relevant For Firms Floating Moderate-Sized IPOs?" Annals of Finance, 3(3), July, 297-327. Publisher's official version: http://dx.doi.org/10.1007/s10436-006-0054-y.Open Access version: http://kuscholarworks.ku.edu/dspace/.

\section{Table A.2. Test Results Across Industries by Frequency of IPOs}

SIC4 Industry Description

181 Ornamental Floriculture and Nursery Products 742 Veterinary Services for Animal Specialties 1041 Gold Ores

1044 Silver Ores

1221 Bituminous Coal and Lignite Surface Mining

1311 Crude Petroleum and Natural Gas

1381 Drilling Oil and Gas Wells

1382 Oil and Gas Field Exploration Services

1389 Oil and Gas Field Services, NEC

1521 General Contractors-Single-Family Houses

1531 Operative Builders

1629 Heavy Construction, NEC

1731 Electrical Work

1799 Special Trade Contractors, NEC

2015 Poultry Slaughtering and Processing

2026 Fluid Milk

2038 Frozen Specialties, NEC

2064 Candy and Other Confectionery Products

2068 Salted and Roasted Nuts and Seeds

2082 Malt Beverages

2086 Bottled and Canned Soft Drinks and Carbonated 2087 Flavoring Extracts and Flavoring Syrups NEC 2095 Roasted Coffee

2099 Food Preparations, NEC

2211 Broadwoven Fabric Mills, Cotton

2221 Broadwoven Fabric Mills, Manmade Fiber and Si

2231 Broadwoven Fabric Mills, Wool (Including Dyei

2253 Knit Outerwear Mills

2325 Men's and Boys' Trousers and Slacks

2326 Men's and Boys' Work Clothing

2329 Men's and Boys' Clothing, NEC

2331 Women's, Misses', and Juniors' Blouses and Sh

2335 Women's, Misses', and Juniors' Dresses

2337 Women's, Misses' and Juniors' Suits, Skirts,

2421 Sawmills and Planing Mills, General

2434 Wood Kitchen Cabinets

2451 Mobile Homes

2452 Prefabricated Wood Buildings and Components

2511 Wood Household Furniture, Except Upholstered

2514 Metal Household Furniture

2631 Paperboard Mills

2675 Die-Cut Paper and Paperboard and Cardboard

2676 Sanitary Paper Products

2711 Newspapers: Publishing, or Publishing and $\mathrm{Pr}$ 2731 Books: Publishing, or Publishing and Printing 2741 Miscellaneous Publishing

2752 Commercial Printing, Lithographic

2759 Commercial Printing, NEC

2819 Industrial Inorganic Chemicals, NEC

2821 Plastics Material and Synthetic Resins, and N 2833 Medicinal Chemicals and Botanical Products

2834 Pharmaceutical Preparations

2835 In Vitro and In Vivo Diagnostic Substances

2836 Biological Products, Except Diagnostic Substa

2844 Perfumes, Cosmetics, and Other Toilet Prepara

2869 Industrial Organic Chemicals, NEC

2879 Pesticides and Agricultural Chemicals, NEC

2911 Petroleum Refining

3021 Rubber and Plastics Footwear

3081 Unsupported Plastics Film and Sheet

3089 Plastics Products, NEC

3143 Men's Footwear, Except Athletic

3144 Women's Footwear, Except Athletic

3299 Nonmetallic Mineral Products, NEC

3312 Steel Works, Blast Furnaces (Including Coke O

3316 Cold-Rolled Steel Sheet, Strip, and Bars

3317 Steel Pipe and Tubes

3321 Gray and Ductile Iron Foundries

3351 Rolling, Drawing, and Extruding of Copper

3357 Drawing and Insulating of Nonferrous Wire

3411 Metal Cans

3423 Hand and Edge Tools, Except Machine Tools and

3432 Plumbing Fixture Fittings and Trim

$\begin{array}{lllll}1985-2003 & 1985-1987 & 1988-1994 & 1995-1998 & 1999-2003 \\ \text { freq exists } & \text { freq exists } & \text { freq } \quad \text { exists } & \text { freq exists } & \text { freq exists }\end{array}$

\begin{tabular}{|c|c|c|c|c|c|c|c|c|}
\hline 2 & 0 & & & & & & & \\
\hline 2 & 0 & & & & & 2 & 0 & \\
\hline 5 & 0 & 4 & 0 & & & & & \\
\hline 2 & 0 & & & & & & & \\
\hline 2 & 0 & & & & & & & \\
\hline 33 & 0 & & & 17 & 0 & 11 & 0 & 5 \\
\hline 4 & 0 & & & 2 & 0 & 2 & 0 & \\
\hline 3 & 0 & & & & & 2 & 0 & \\
\hline 9 & 1 & & & 3 & 0 & 5 & 1 & \\
\hline 17 & 0 & 2 & 0 & 9 & 0 & 5 & 0 & \\
\hline 5 & 0 & 2 & 0 & 3 & 0 & & & \\
\hline 5 & 0 & & & 3 & 0 & & & \\
\hline 4 & 0 & & & & & 2 & 0 & \\
\hline 2 & 1 & & & 2 & 1 & & & \\
\hline 3 & 1 & 3 & 1 & & & & & \\
\hline
\end{tabular}

20

$5 \quad 0$

30

30

$$
\begin{array}{ll}
2 & 0 \\
2 & 0
\end{array}
$$

20020

21

0

20

20

20

20

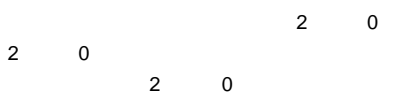

$\begin{array}{rrrrrrrr} & & & & 4 & 0 & & \\ 3 & 0 & 35 & 0 & 23 & 1 & 27 & 0 \\ 2 & 0 & 4 & 0 & 7 & 0 & 3 & 0 \\ 6 & 1 & 13 & 0 & 22 & 0 & 15 & 0 \\ 2 & 0 & & & 2 & 0 & & \end{array}$

20

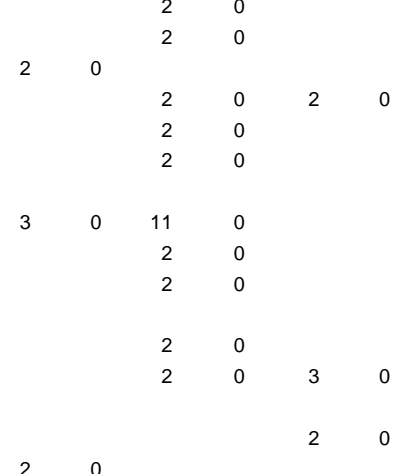


"Kulkarni, Kedar and Tarun Sabarwal (2007): “To What Extent Are Investment Bank-Differentiating Factors Relevant For Firms Floating Moderate-Sized IPOs?" Annals of Finance, 3(3), July, 297-327. Publisher's official version: http://dx.doi.org/10.1007/s10436-006-0054-y.Open Access version: http://kuscholarworks.ku.edu/dspace/.

3462 Iron and Steel Forgings 3465 Automotive Stamping

3469 Metal Stamping, NEC

3523 Farm Machinery and Equipment

3531 Construction Machinery and Equipment

3533 Oil and Gas Field Machinery and Equipment

3541 Machine Tools, Metal Cutting Type

3555 Printing Trades Machinery and Equipment

3556 Food Products Machinery

3559 Special Industry Machinery, NEC

3561 Pumps and Pumping Equipment

3569 General Industrial Machinery and Equipment, N

3571 Electronic Computers

3572 Computer Storage Devices

3575 Computer Terminals

3577 Computer Peripheral Equipment, NEC

3578 Calculating and Accounting Machines, Except E

3585 Air-Conditioning and Warm Air Heating Equipme

3589 Service Industry Machinery, NEC

3629 Electrical Industrial Apparatus, NEC

3634 Electric Housewares and Fans

3641 Electric Lamp Bulbs and Tubes

3645 Residential Electric Lighting Fixtures

3651 Household Audio and Video Equipment

3652 Phonograph Records and Prerecorded Audio Tape

3661 Telephone and Telegraph Apparatus

3663 Radio and Television Broadcasting and Communi

3669 Communications Equipment, NEC

3672 Printed Circuit Boards

3674 Semiconductors and Related Devices

3679 Electronic Components, NEC

3691 Storage Batteries

3699 Electrical Machinery, Equipment, and Supplies

3713 Truck and Bus Bodies

3714 Motor Vehicle Parts and Accessories

3715 Truck Trailers

3724 Aircraft Engines and Engine Parts

3728 Aircraft Parts and Auxiliary Equipment, NEC

3731 Ship Building and Repairing

3743 Railroad Equipment

3751 Motorcycles, Bicycles, and Parts

3792 Travel Trailers and Campers

3812 Search, Detection, Navigation, Guidance, Aero

3823 Industrial Instruments for Measurement, Displ

3825 Instruments for Measuring and Testing of Elec

3826 Laboratory Analytical Instruments

3827 Optical Instruments and Lenses

3829 Measuring and Controlling Devices, NEC

3841 Surgical and Medical Instruments and Apparatu

3842 Orthopedic, Prosthetic, and Surgical Applianc

3844 X-Ray Apparatus and Tubes and Related Irradia

3845 Electromedical and Electrotherapeutic Apparat

3851 Ophthalmic Goods

3861 Photographic Equipment and Supplies

3911 Jewelry, Precious Meta

3942 Dolls and Stuffed Toys

3944 Games, Toys, and Children's Vehicles, Except

3949 Sporting and Athletic Goods, NEC

3955 Carbon Paper and Inked Ribbons

3999 Manufacturing Industries, NEC

4011 Railroads, Line-haul Operating

4119 Local Passenger Transportation, NEC

4212 Local Trucking Without Storage

4213 Trucking, Except Local

4215 Courier Services Except by Air

4226 Special Warehousing and Storage, NEC

4412 Deep Sea Foreign Transportation of Freight

4499 Water Transportation Services, NEC

4512 Air Transportation, Scheduled

4522 Air Transportation, Nonscheduled

4724 Travel Agencies

4731 Arrangement of Transportation of Freight and

4812 Radiotelephone Communications

4813 Telephone Communications, Except Radiotelepho

4822 Telegraph and Other Message Communications

4832 Radio Broadcasting Stations

4833 Television Broadcasting Stations

4841 Cable and Other Pay Television Services

4899 Communications Services, NEC

4911 Electric Services

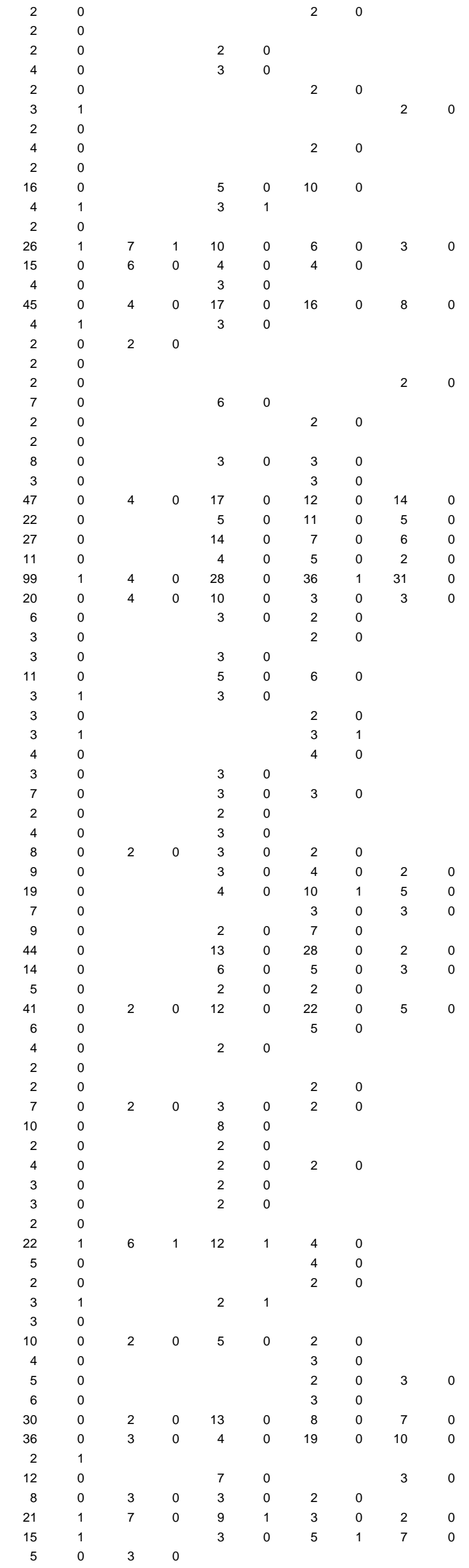


"Kulkarni, Kedar and Tarun Sabarwal (2007): “To What Extent Are Investment Bank-Differentiating Factors Relevant For Firms Floating Moderate-Sized IPOs?" Annals of Finance, 3(3), July, 297-327. Publisher's official version: http://dx.doi.org/10.1007/s10436-006-0054-y.Open Access version: http://kuscholarworks.ku.edu/dspace/.

4922 Natural Gas Transmission

4923 Natural Gas Transmission and Distribution

4931 Electric and Other Services Combined

4952 Sewerage Systems

4953 Refuse Systems

5012 Automobiles and Other Motor Vehicles

5013 Motor Vehicle Supplies and New Parts

5021 Furniture

5031 Lumber, Plywood, Millwork, and Wood Panels

5044 Office Equipment

5045 Computers and Computer Peripheral Equipment a

5047 Medical, Dental, and Hospital Equipment and S

5051 Metals Service Centers and Offices

5063 Electrical Apparatus and Equipment Wiring Sup

5064 Electrical Appliances, Television and Radio S

5065 Electronic Parts and Equipment, NEC

5072 Hardware

5084 Industrial Machinery and Equipment

5085 Industrial Supplies

5091 Sporting and Recreational Goods and Supplies

5092 Toys and Hobby Goods and Supplies

5093 Scrap and Waste Materials

5099 Durable Goods, NEC

5112 Stationery and Office Supplies

5141 Groceries, General Line

5149 Groceries and Related Products, NEC

5159 Farm-Product Raw Materials, NEC

5191 Farm Supplies

5192 Books, Periodicals, and Newspapers

5193 Flowers, Nursery Stock, and Florists' Supplie

5211 Lumber and Other Building Materials Dealers

5251 Hardware Stores

5261 Retail Nurseries, Lawn and Garden Supply Stor

5311 Department Stores

5331 Variety Stores

5399 Miscellaneous General Merchandise Stores

5411 Grocery Stores

5499 Miscellaneous Food Stores

5511 Motor Vehicle Dealers (New and Used)

5521 Motor Vehicle Dealers (Used Only)

5531 Auto and Home Supply Stores

5551 Boat Dealers

5611 Men's and Boys' Clothing and Accessory Stores 5621 Women's Clothing Stores

5641 Children's and Infants' Wear Stores

5651 Family Clothing Stores

5661 Shoe Stores

5699 Miscellaneous Apparel and Accessory Stores

5712 Furniture Stores

5719 Miscellaneous Homefurnishings Stores

5722 Household Appliance Stores

5731 Radio, Television, and Consumer Electronics S

5734 Computer and Computer Software Stores

5735 Record and Prerecorded Tape Stores

5812 Eating and Drinking Places

5912 Drug Stores and Proprietary Stores

5932 Used Merchandise Stores

5941 Sporting Goods Stores and Bicycle Shops

5942 Book Stores

5943 Stationery Stores

5944 Jewelry Stores

5945 Hobby, Toy, and Game Shops

5947 Gift, Novelty, and Souvenir Shops

5961 Catalog and Mail-Order Houses

5999 Miscellaneous Retail Stores, NEC

6021 National Commercial Banks

6022 State Commercial Banks

6035 Savings Institutions, Federally Chartered

6036 Savings institutions, Not Federally Chartered

6099 Functions Related to Deposit Banking, NEC

6141 Personal Credit Institutions

6159 Miscellaneous Business Credit Institutions

6162 Mortgage Bankers and Loan Correspondents

6211 Security Brokers, Dealers, and Flotation Comp

6282 Investment Advice

6311 Life Insurance

6324 Hospital and Medical Service Plans

6331 Fire, Marine, and Casualty Insurance

6351 Surety Insurance

6371 Pension, Health, and Welfare Funds

\begin{tabular}{|c|c|c|c|c|c|c|c|c|c|}
\hline 3 & 0 & & & 2 & 0 & & & & \\
\hline 2 & 0 & & & & & & & & \\
\hline 2 & 0 & & & & & & & & \\
\hline 2 & 0 & & & & & & & & \\
\hline 17 & 1 & 2 & 0 & 8 & 0 & 6 & 0 & & \\
\hline 2 & 0 & & & 2 & 0 & & & & \\
\hline 3 & 0 & & & & & 2 & 0 & & \\
\hline 2 & 0 & & & 2 & 0 & & & & \\
\hline 2 & 0 & & & & & & & & \\
\hline 2 & 0 & & & & & & & & \\
\hline 11 & 0 & 2 & 0 & 4 & 1 & 4 & 0 & & \\
\hline 6 & 0 & & & 3 & 0 & 2 & 0 & & \\
\hline 2 & 0 & & & & & & & & \\
\hline 2 & 0 & & & & & & & & \\
\hline 2 & 0 & 2 & 0 & & & & & & \\
\hline 4 & 0 & & & 2 & 0 & & & & \\
\hline 2 & 0 & & & & & & & & \\
\hline 3 & 0 & & & & & 3 & 0 & & \\
\hline 2 & 0 & & & & & 2 & 0 & & \\
\hline 4 & 0 & & & 2 & 0 & 2 & 0 & & \\
\hline 2 & 0 & & & & & & & & \\
\hline 2 & 0 & & & & & & & & \\
\hline 3 & 0 & & & & & & & & \\
\hline 3 & 0 & & & & & 3 & 0 & & \\
\hline 5 & 1 & & & 3 & 0 & 2 & 0 & & \\
\hline 3 & 0 & & & & & 2 & 0 & & \\
\hline 2 & 0 & & & 2 & 0 & & & & \\
\hline 2 & 0 & & & 2 & 0 & & & & \\
\hline 3 & 0 & 2 & 0 & & & & & & \\
\hline 2 & 0 & & & & & & & & \\
\hline 4 & 0 & & & 4 & 0 & & & & \\
\hline 4 & 0 & & & 3 & 0 & & & & \\
\hline 3 & 0 & & & 2 & 0 & & & & \\
\hline 5 & 0 & & & 3 & 0 & & & & \\
\hline 6 & 0 & 2 & 0 & & & 3 & 0 & & \\
\hline 6 & 0 & 3 & 0 & 2 & 0 & & & & \\
\hline 13 & 0 & 7 & 0 & 5 & 0 & & & & \\
\hline 4 & 0 & & & & & 2 & 0 & & \\
\hline 5 & 0 & & & & & 5 & 0 & & \\
\hline 2 & 0 & & & 2 & 0 & & & & \\
\hline 7 & 0 & 2 & 0 & 5 & 0 & & & & \\
\hline 2 & 0 & & & & & & & & \\
\hline 4 & 0 & & & 4 & 0 & & & & \\
\hline 12 & 0 & 4 & 0 & 6 & 0 & & & & \\
\hline 3 & 0 & & & 2 & 0 & & & & \\
\hline 8 & 0 & 3 & 0 & 3 & 1 & 2 & 0 & & \\
\hline 5 & 0 & & & 3 & 0 & & & & \\
\hline 2 & 0 & & & & & & & & \\
\hline 6 & 0 & 2 & 0 & 3 & 0 & & & & \\
\hline 3 & 0 & & & 2 & 0 & & & & \\
\hline 3 & 0 & 3 & 0 & & & & & & \\
\hline 7 & 0 & 3 & 0 & 2 & 0 & & & & \\
\hline 5 & 0 & & & 2 & 0 & 2 & 0 & & \\
\hline 6 & 0 & 3 & 0 & & & 2 & 0 & & \\
\hline 45 & 1 & & & 28 & 1 & 9 & 0 & 7 & 0 \\
\hline 8 & 0 & 2 & 0 & 3 & 1 & & & 2 & 0 \\
\hline 2 & 0 & & & & & & & & \\
\hline 6 & 0 & & & 3 & 0 & & & 2 & 0 \\
\hline 4 & 0 & & & & & 2 & 0 & & \\
\hline 3 & 0 & & & 3 & 0 & & & & \\
\hline 6 & 0 & 2 & 0 & 2 & 0 & 2 & 0 & & \\
\hline 5 & 0 & & & & & & & 2 & 0 \\
\hline 6 & 1 & & & 2 & 0 & & & 3 & 1 \\
\hline 25 & 0 & 5 & 0 & 3 & 1 & 9 & 0 & 8 & 0 \\
\hline 10 & 0 & & & 4 & 0 & 3 & 0 & 2 & 0 \\
\hline 9 & 0 & 2 & 0 & & & 3 & 0 & 3 & 0 \\
\hline 16 & 0 & 7 & 0 & 2 & 0 & 6 & 1 & & \\
\hline 30 & 1 & 23 & 0 & 5 & 0 & 2 & 0 & & \\
\hline 24 & 1 & 18 & 1 & 4 & 0 & 2 & 0 & & \\
\hline 3 & 0 & & & & & & & & \\
\hline 17 & 0 & & & 6 & 0 & 10 & 0 & & \\
\hline 6 & 0 & & & & & 4 & 0 & & \\
\hline 25 & 1 & & & 11 & 1 & 9 & 0 & 4 & 0 \\
\hline 15 & 0 & 6 & 0 & 2 & 0 & 5 & 0 & 2 & 0 \\
\hline 7 & 0 & 4 & 0 & 2 & 0 & & & & \\
\hline 20 & 0 & 7 & 0 & 5 & 0 & 7 & 0 & & \\
\hline 17 & 0 & & & 10 & 0 & 5 & 0 & 2 & 0 \\
\hline 20 & 0 & 4 & 0 & 9 & 0 & 5 & 0 & 2 & 1 \\
\hline 7 & 0 & & & 3 & 0 & 3 & 0 & & \\
\hline 2 & 0 & & & 2 & 0 & & & & \\
\hline
\end{tabular}


"Kulkarni, Kedar and Tarun Sabarwal (2007): “To What Extent Are Investment Bank-Differentiating Factors Relevant For Firms Floating Moderate-Sized IPOs?" Annals of Finance, 3(3), July, 297-327. Publisher's official version: http://dx.doi.org/10.1007/s10436-006-0054-y.Open Access version: http://kuscholarworks.ku.edu/dspace/.

6411 Insurance Agents, Brokers, and Service 6512 Operators of Nonresidential Buildings 6531 Real Estate Agents and Managers

6552 Land Subdividers and Developers, Except Cemet 6712 Offices of Bank Holding Companies 6719 Offices of Holding Companies, NEC 6722 Management Investment Offices, Open-End 7011 Hotels and Motels

7021 Rooming and Boarding Houses

7231 Beauty Shops

7261 Funeral Services and Crematories

7311 Advertising Agencies

7312 Outdoor Advertising Services

7319 Advertising, NEC

7322 Adjustment and Collection Services

7331 Direct Mail Advertising Services

7352 Medical Equipment Rental and Leasing

7359 Equipment Rental and Leasing, NEC

7361 Employment Agencies

7363 Help Supply Services

7371 Computer Programming Services

7372 Prepackaged Software

7373 Computer Integrated Systems Design

7374 Computer Processing and Data Preparation and

7375 Information Retrieval Services

7376 Computer Facilities Management Services

7378 Computer Maintenance and Repair

7379 Computer Related Services, NEC

7381 Detective, Guard, and Armored Car Services

7382 Security Systems Services

7389 Business Services, NEC

7514 Passenger Car Rental

7549 Automotive Services, Except Repair and Carwas 7812 Motion Picture and Video Tape Production 7819 Services Allied to Motion Picture Production 7822 Motion Picture and Video Tape Distribution 7832 Motion Picture Theaters, Except Drive-In 7841 Video Tape Rental

7941 Professional Sports Clubs and Promoters 7948 Racing, Including Track Operations 7993 Coin-Operated Amusement Devices 7999 Amusement and Recreation Services, NEC 8011 Offices and Clinics of Doctors of Medicine 8021 Offices and Clinics of Dentists 8042 Offices and Clinics of Optometrists 8051 Skilled Nursing Care Facilities 8059 Nursing and Personal Care Facilities, NEC 8062 General Medical and Surgical Hospitals 8069 Specialty Hospitals, Except Psychiatric 8071 Medical Laboratories

8082 Home Health Care Services

8092 Kidney Dialysis Centers

8093 Specialty Outpatient Facilities, NEC

8099 Health and Allied Services, NEC

8221 Colleges, Universities, and Professional Scho

8299 Schools and Educational Services, NEC

8351 Child Day Care Services

8361 Residential Care

8711 Engineering Services

8721 Accounting, Auditing, and Bookkeeping Service 8731 Commercial Physical and Biological Research 8732 Commercial Economic, Sociological, and Educat 8734 Testing Laboratories

8741 Management Services

8742 Management Consulting Services

8744 Facilities Support Management Services

8748 Business Consulting Services, NEC

Notes

1 freq. $=$ frequency of moderate-sized IPOs

2 exists $=1$ iff differentiation exists

3 No entry iff number of IPOs $<=1$ (test is not defined)

\begin{tabular}{|c|c|c|c|c|c|c|c|c|c|}
\hline 7 & 0 & & & 2 & 0 & 4 & 0 & & \\
\hline 2 & 0 & & & & & & & & \\
\hline 2 & 0 & & & & & 2 & 0 & & \\
\hline 2 & 0 & 2 & 0 & & & & & & \\
\hline 7 & 1 & & & & & 3 & 1 & 3 & 0 \\
\hline 3 & 0 & & & & & 2 & 0 & & \\
\hline 2 & 0 & 2 & 0 & & & & & & \\
\hline 20 & 1 & 3 & 0 & 5 & 0 & 12 & 1 & & \\
\hline 2 & 0 & & & & & 2 & 0 & & \\
\hline 2 & 0 & & & & & & & & \\
\hline 3 & 0 & & & 2 & 0 & & & & \\
\hline 10 & 0 & & & & & 3 & 0 & 6 & 0 \\
\hline 2 & 0 & & & & & 2 & 0 & & \\
\hline 3 & 0 & & & & & 2 & 0 & & \\
\hline 2 & 0 & & & & & & & & \\
\hline 6 & 0 & & & 3 & 0 & 3 & 0 & & \\
\hline 2 & 0 & & & 2 & 0 & & & & \\
\hline 10 & 0 & & & 2 & 0 & 7 & 0 & & \\
\hline 3 & 0 & & & & & & & 3 & 0 \\
\hline 17 & 0 & & & 4 & 0 & 13 & 0 & & \\
\hline 58 & 0 & & & 5 & 0 & 42 & 0 & 11 & 0 \\
\hline 353 & 1 & 13 & 1 & 65 & 1 & 143 & 1 & 132 & 0 \\
\hline 91 & 0 & 4 & 0 & 18 & 0 & 43 & 0 & 26 & 0 \\
\hline 32 & 0 & 5 & 0 & 6 & 0 & 13 & 0 & 8 & 0 \\
\hline 84 & 1 & & & 8 & 0 & 21 & 0 & 55 & 0 \\
\hline 3 & 0 & & & & & 2 & 0 & & \\
\hline 2 & 0 & & & 2 & 0 & & & & \\
\hline 34 & 0 & & & 2 & 0 & 15 & 0 & 16 & 0 \\
\hline 2 & 0 & & & 2 & 0 & & & & \\
\hline 2 & 0 & & & & & & & & \\
\hline 67 & 0 & & & 4 & 0 & 31 & 0 & 32 & 0 \\
\hline 3 & 0 & 2 & 0 & & & & & & \\
\hline 2 & 0 & & & & & & & & \\
\hline 7 & 0 & 3 & 1 & 2 & 0 & 2 & 0 & & \\
\hline 4 & 1 & & & 2 & 0 & & & & \\
\hline 3 & 0 & & & 2 & 0 & & & & \\
\hline 3 & 0 & & & 2 & 0 & & & & \\
\hline 5 & 0 & & & & & 2 & 0 & & \\
\hline 2 & 0 & & & & & & & & \\
\hline 4 & 0 & & & & & 4 & 0 & & \\
\hline 2 & 0 & & & & & & & & \\
\hline 5 & 0 & & & 3 & 0 & 2 & 0 & & \\
\hline 18 & 0 & 4 & 0 & 9 & 0 & 5 & 0 & & \\
\hline 2 & 0 & & & & & 2 & 0 & & \\
\hline 2 & 0 & & & & & & & & \\
\hline 14 & 1 & & & 10 & 0 & 3 & 1 & & \\
\hline 5 & 1 & & & & & 5 & 1 & & \\
\hline 8 & 0 & 3 & 1 & 2 & 0 & 3 & 1 & & \\
\hline 5 & 0 & & & 5 & 0 & & & & \\
\hline 10 & 0 & & & 6 & 0 & & & 2 & 0 \\
\hline 9 & 1 & & & 3 & 0 & 4 & 0 & & \\
\hline 4 & 0 & & & 2 & 0 & & & & \\
\hline 12 & 0 & 2 & 0 & 5 & 0 & 4 & 0 & & \\
\hline 20 & 1 & & & 8 & 0 & 8 & 1 & 3 & 0 \\
\hline 4 & 1 & & & & & 2 & 0 & & \\
\hline 13 & 1 & & & 3 & 1 & 3 & 0 & 7 & 0 \\
\hline 3 & 0 & & & & & 2 & 0 & & \\
\hline 4 & 0 & & & & & 4 & 0 & & \\
\hline 9 & 0 & 4 & 0 & 4 & 0 & & & & \\
\hline 2 & 0 & & & & & & & & \\
\hline 34 & 0 & & & 8 & 0 & 13 & 0 & 12 & 0 \\
\hline 10 & 0 & & & 2 & 0 & 3 & 0 & 5 & 0 \\
\hline 3 & 0 & & & & & 2 & 0 & & \\
\hline 13 & 0 & & & 3 & 0 & 9 & 0 & & \\
\hline 14 & 0 & & & 2 & 0 & 8 & 0 & 4 & 0 \\
\hline 3 & 0 & & & & & 2 & 0 & & \\
\hline 6 & 0 & 2 & 0 & 2 & 0 & 2 & 0 & & \\
\hline
\end{tabular}


"Kulkarni, Kedar and Tarun Sabarwal (2007): “To What Extent Are Investment Bank-Differentiating Factors Relevant For Firms Floating Moderate-Sized IPOs?"

Annals of Finance, 3(3), July, 297-327. Publisher's official version: http://dx.doi.org/10.1007/s10436-006-0054-y.Open Access version: http://kuscholarworks.ku.edu/dspace/.

Table A.3. Details For Industries With Differentiation (SIC4 and SIC3)

SIC4

1985-2003
$1988-94$
SIC3

1999-03
1985-87
1988-94
1995-98 1999-03

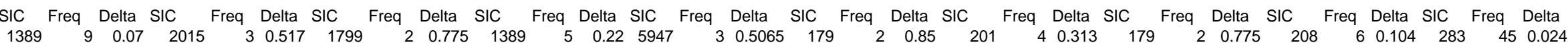

$\begin{array}{llll}1389 & 9 & 0.07 & 2015 \\ 1799 & 2 & 0.85 & 2836\end{array}$

$\begin{array}{lll}0.517 & 1799 \\ 6 & 0.146 & 2331\end{array}$

$\begin{array}{llll}\text { Freq Delta SIC } & \\ 201 & 4 & 0.313\end{array}$ $\begin{array}{llll}3 & 0.433 & 3571\end{array}$ $\begin{array}{lrr}6 & 0.146 & 2331 \\ 7 & 0.25 & 3561\end{array}$

$\begin{array}{llllll}2 & 1.151 & 2834 & 23 & 0.029 & 6331\end{array}$

$2-0.573 \quad 201$

40.258

$\begin{array}{lll}421 & 6 & 0.278\end{array}$

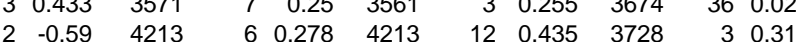

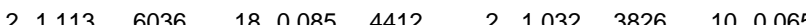

$\begin{array}{lllllllllll}88 & 0.009 & 7372 & 13 & 0.196 & 4841 & 9 & 0.088 & 4899 & 5 & 0.598\end{array}$

$\begin{array}{llllllllllll}3 & 0.251 & 7812 & 3 & 0.457 & 5045 & 4 & 0.182 & 6022 & 6 & 0.274\end{array}$

$\begin{array}{lllllllllll}4 & 0.177 & 8062 & 3 & 0.294 & 5651 & 3 & 0.264 & 6712 & 3 & 0.483\end{array}$

$\begin{array}{rrrrrrrr}26 & 0.023 & 5812 & 28 & 0.076 & 7011 & 12 & 0.136 \\ 4 & 0.159 & 5912 & 3 & 0.513 & 7372 & 143 & 0.022\end{array}$

$\begin{array}{llll}4 & 0.159\end{array}$

$\begin{array}{rrrrrr}5912 & 3 & 0.513 & 7372 & 143 & 0.022 \\ 5961 & 3 & 0.369 & 8051 & 3 & 0.34\end{array}$

30.196

$\begin{array}{rllll}3 & 0.369 & 8051 & 3 & 0.34 \\ 11 & 0.085 & 8059 & 5 & 0.363\end{array}$

30.306

$\begin{array}{lllll}65 & 0.024 & 8062 & 3 & 0.229\end{array}$

$\begin{array}{ll}22 & 0.36\end{array}$

$\begin{array}{llllll}3 & 0.352 & 8099 & 8 & 0.283\end{array}$

$\begin{array}{rrr}4412 & 3 & 0.238\end{array}$

$\begin{array}{lll}4422 & 3 & 0.238 \\ 4822 & -0.42\end{array}$

$\begin{array}{lrr}4822 & 2 & -0.42 \\ 4841 & 21 & 0.025\end{array}$

$\begin{array}{lll}4899 & 15 & 0.049\end{array}$

$\begin{array}{lll}4953 & 17 & 0.043\end{array}$

$\begin{array}{lll}5141 & 5 & 0.148\end{array}$

$5812 \quad 450.043$

$\begin{array}{lll}5947 & 6 & 0.165\end{array}$

$\begin{array}{lll}6035 & 30 & 0.063\end{array}$

$\begin{array}{lll}6036 & 24 & 0.097\end{array}$

$\begin{array}{rrr}6162 & 25 & 0.024 \\ 6712 & 7 & 0.203\end{array}$

$7011 \quad 200.203$

$\begin{array}{lrr}7011 & 20 & 0.075 \\ 7372 & 353 & 0.011\end{array}$

$7375 \quad 3530.011$

$\begin{array}{lll}7819 & 4 & 0.172\end{array}$

$8051 \quad 14 \quad 0.085$

$8059 \quad 5 \quad 0.401$

$8082 \quad 90.062$

$\begin{array}{lll}8099 & 20 & 0.073\end{array}$

$\begin{array}{rrr}8221 & 4 & 0.239 \\ 8299 & 13 & 0.114\end{array}$

Wt. Average $\quad 0.045$

0.207 
"Kulkarni, Kedar and Tarun Sabarwal (2007): "To What Extent Are Investment Bank-Differentiating Factors Relevant For Firms Floating Moderate-Sized IPOs?"

Annals of Finance, 3(3), July, 297-327. Publisher's official version: http://dx.doi.org/10.1007/s10436-006-0054-y.Open Access version: http://kuscholarworks.ku.edu/dspace/.

\section{Table A.4. Details For Industries With Differentiation (SIC2)}

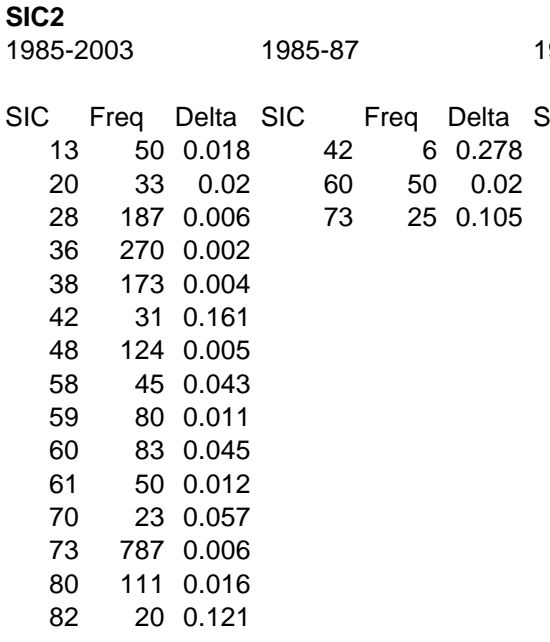

988-94

$1995-98$

1999-03

Wt. Average 0.013

Freq Delta SIC

$\begin{array}{lll}\text { Freq Delta SIC } \\ 90 & 0.079\end{array}$

SIC Freq Delta

$\begin{array}{rrr}15 & 12 & 0.066 \\ 17 & 2 & 0.775\end{array}$

$\begin{array}{lll}17 & 2 & 0.775 \\ 22 & 7 & 0.101\end{array}$

$\begin{array}{lll}22 & 7 & 0.101 \\ 31 & 5 & 0.172\end{array}$

$\begin{array}{rrr}31 & 5 & 0.172 \\ 42 & 14 & 0.39\end{array}$

$\begin{array}{lll}56 & 19 & 0.058\end{array}$

$\begin{array}{lll}58 & 28 & 0.076\end{array}$

$\begin{array}{lll}61 & 18 & 0.039\end{array}$

$\begin{array}{lll}73 & 126 & 0.011\end{array}$

$\begin{array}{rrr}73 & 126 & 0.011 \\ 80 & 51 & 0.017\end{array}$

$\begin{array}{rrr}80 & 51 & 0.017 \\ 82 & 4 & 0.172\end{array}$

$\begin{array}{lll}28 & 64 & 0.014\end{array}$

$\begin{array}{lll}28 & 47 & 0.019\end{array}$

$\begin{array}{lr}6 & 0.11\end{array}$

$\begin{array}{lll}80 & 8 & 0.089\end{array}$

$\begin{array}{lll}57 & 7 & 0.119\end{array}$

$\begin{array}{lll}60 & 15 & 0.112\end{array}$

$\begin{array}{lll}65 & 4 & 0.203\end{array}$

$\begin{array}{lll}70 & 14 & 0.115\end{array}$

$\begin{array}{llll}73 & 344 & 0.005\end{array}$

0.057

0.022

0.01

Descriptions of SIC2 Industries Listed Above

13 Oil and gas extraction

15 General building contractors

17 Special trade contractors

20 Food and kindred products

22 Textile mill products

28 Chemicals and allied products

31 Leather and leather products

36 Electrical and electronic equipment

38 Instruments and related products

42 Motor freight transportation and warehousing

48 Communications

56 Apparel and accessory stores

57 Furniture, home furnishings and equipment stores

58 Eating and drinking places

59 Miscellaneous retail

60 Depository institutions

61 Nondepository credit institutions

65 Real estate

70 Hotels, rooming houses, camps, and other lodging places

73 Business services

80 Health services

82 Educational services 